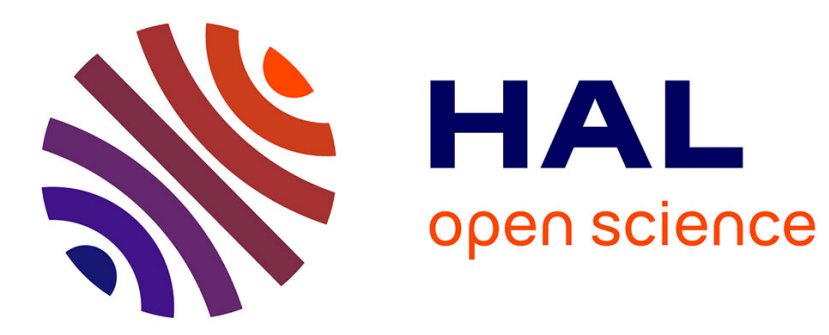

\title{
Bubble Coalescence and Percolation Threshold in Expanding Rhyolitic Magma
}

Thomas Giachetti, Helge Gonnermann, James Gardner, Alain Burgisser, Sahand Hajimirza, Tobias Earley, Nathan Truong, Pamela Toledo

\section{To cite this version:}

Thomas Giachetti, Helge Gonnermann, James Gardner, Alain Burgisser, Sahand Hajimirza, et al.. Bubble Coalescence and Percolation Threshold in Expanding Rhyolitic Magma. Geochemistry, Geophysics, Geosystems, 2019, 20 (2), pp.1054-1074. 10.1029/2018GC008006 . hal-02356533

\section{HAL Id: hal-02356533 \\ https://hal.science/hal-02356533}

Submitted on 8 Nov 2019

HAL is a multi-disciplinary open access archive for the deposit and dissemination of scientific research documents, whether they are published or not. The documents may come from teaching and research institutions in France or abroad, or from public or private research centers.
L'archive ouverte pluridisciplinaire HAL, est destinée au dépôt et à la diffusion de documents scientifiques de niveau recherche, publiés ou non, émanant des établissements d'enseignement et de recherche français ou étrangers, des laboratoires publics ou privés. 


\section{Bubble coalescence and percolation threshold in expanding rhyolitic magma}

Thomas Giachetti ${ }^{1}$, Helge M. Gonnermann ${ }^{2}$, James E. Gardner ${ }^{3}$, Alain

Burgisser $^{4}$, Sahand Hajimirza ${ }^{2}$, Tobias C. Earley ${ }^{1}$, Nathan Truong ${ }^{2}$, and

Pamela Toledo ${ }^{2}$

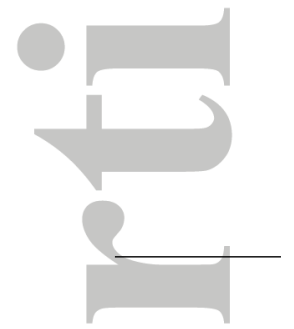

Thomas Giachetti, tgiachet@uoregon.edu

${ }^{1}$ Department of Earth Sciences,

University of Oregon, Eugene, OR, USA.

${ }^{2}$ Department of Earth Science, Rice

University, Houston, Texas, USA.

${ }^{3}$ Jackson School of Geosciences,

University of Texas, Austin, TX, USA.

${ }^{4}$ Univ. Savoie Mont Blanc, CNRS, IRD,

ISTerre, F-73376 Le Bourget du Lac,

France.

This article has been accepted for publication and undergone full peer review but has not been through the copyediting, typesetting, pagination and proofreading process, which may lead to differences between this version and the Version of Record. Please cite this article as doi: 10.1029/2018GC008006

(C)2019 American Geophysical Union. All Rights Reserved. 
Abstract. Coalescence during bubble nucleation and growth in crystalfree rhyolitic melt was experimentally investigated and the percolation threshold, defined as the porosity at which the vesicular melt first becomes permeable, was estimated. Experiments with bubble number densities between $10^{14}$ and $10^{15} \mathrm{~m}^{-3}$ were compared to four suites of rhyolitic Plinian pumices, which have approximately equal bubble number densities. A higher percentage of bubbles in the Plinian samples are coalesced than in their experimental counterparts. Percolation modeling of the experimental samples indicates that all of them are impermeable and have percolation thresholds of approximately $80-90 \%$, irrespective of their porosity. Percolation modeling of the Plinian pumices, all of which have been shown to be permeable, gives a percolation threshold of approximately $60 \%$. The experimental samples fall on a distinct trend in terms of connected vs. total porosity relative to the Plinian samples, which also have a greater melt-bubble structural complexity. The same holds true for experimental samples of lower bubble number densities.

We interpret the comparatively higher coalescence within the Plinian samples to be a consequence of shear deformation of the erupting magma, together with an inherently greater structural complexity resulting from a more complex nucleation process.

\section{Keypoints:}

- The value of percolation threshold is a consequence of geometric and topological properties set during bubble nucleation

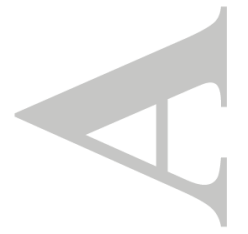

(C)2019 American Geophysical Union. All Rights Reserved. 
- Percolation threshold is positively correlated with the bubble number density

- Percolation threshold is negatively correlated with the index of packing disorder and positively with the mode of the distribution of coordination numbers

- Expanding rhyolitic magma during Plinian eruptions becomes permeable at a porosity of approximately $60 \%$
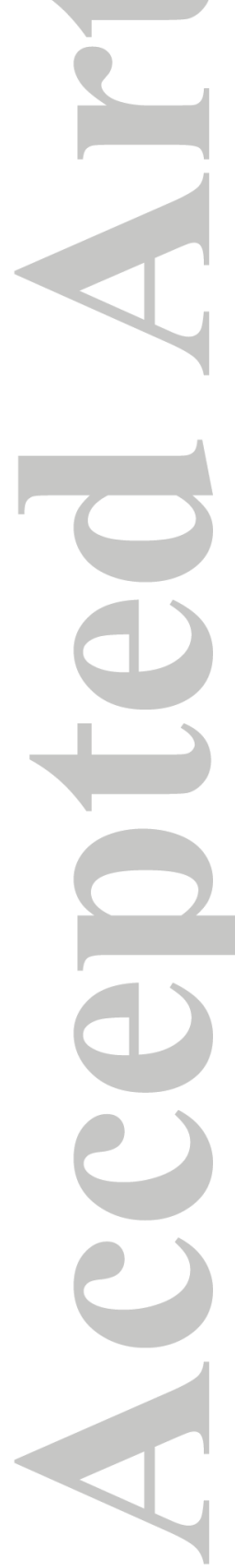


\section{Introduction}

Explosive volcanic eruptions are modulated by magma degassing (Sparks, 1978 ; Jaupart \& Allègre, 1991 ; Woods \& Koyaguchi, 1994 ; Gonnermann \& Manga, 2007). Bubbles of supercritical fluid, consisting predominantly of water and lesser amounts of carbon dioxide, sulfur, halogens and other volatiles, nucleate and grow during magma ascent. This vesiculation process is a consequence of decreasing magma pressure, which results in volatile supersaturation and expansion of the exsolved volatiles (Toramaru, 1990 ; Liu, Zhang, \& Behrens, 2005 ; Zhang, Xu, Zhu, \& Wang, 2007). The high viscosity of rhyolitic melt can limit the rate at which bubbles grow during decompression and the pressure inside bubbles may decrease at a slower rate than that of the surrounding magma, resulting in bubble overpressure (N. G. Lensky, Lyakhovsky, \& Navon, 2001 ; Gonnermann \& Manga, 2007). During Plinian eruptions it is thought that this overpressure reaches a critical value and causes the ascending magma to fragment (McBirney \& Murase, 1970 ; Sparks, 1978 ; Alidibirov, 1994 ; Dingwell, 1996 ; Zhang, 1999 ; Spieler et al., 2004 ; Gonnermann, 2015). To what extent outgassing, the net loss of exsolved volatiles from within the ascending magma by permeable flow, can modulate explosivity and eruptive style remains a matter of debate (Eichelberger, Carrigan, Westrich, \& Price, 1986 ; Westrich Eichelberger, 1994 ; Klug \& Cashman, 1996 ; Dingwell, 1996 ; Wright, Roberts, \& Cashman, 2006 ; Mueller, Scheu, Spieler, \& Dingwell, 2008 ; Rust \& Cashman, 2011 ; Degruyter, Bachmann, Burgisser, \& Manga, 2012 ; Lavallée et al., 2013 ; Gonnermann,

2015 ; Heap \& Kennedy, 2016 ; Burgisser, Chevalier, Gardner, \& Castro, 2017 ; Kushnir, Martel, Champallier, \& Arbaret, 2017).

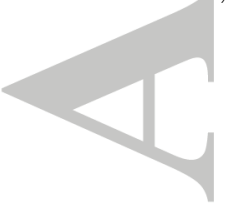

(C)2019 American Geophysical Union. All Rights Reserved. 
As bubbles nucleate and grow, either during eruptive magma ascent or during decompression experiments, inter-bubble melt films are thinned to the point of rupture and associated bubble coalescence (Proussevitch, Sahagian, \& Kutolin, 1993 ; Martula, Hasegawa, Lloyd, \& Bonnecaze, 2000 ; Okumura, Nakamura, \& Tsuchiyama, 2006 ; Gardner, 2007 ; Castro, Burgisser, Schipper, \& Mancini, 2012 ; Nguyen et al., 2013 ; Martel \& IaconoMarziano, 2015). An interconnected network of bubbles may evolve so that the magma becomes permeable, allowing for porous flow of fluid contained within. The work presented herein focuses on this process. The porosity at which magma first becomes permeable is called the percolation threshold, $\phi_{\text {cr }}$ (Sahimi, 1994 ; Klug \& Cashman, 1996 ; Saar \& Manga, 1999). At total porosities of $\phi_{\text {tot }}>\phi_{\text {cr }}$ permeability is thought to be a nonlinear function of the volume fraction of bubbles (Blower, 2001a ; Wright, Cashman, Gottesfeld, \& Roberts, 2009 ; Rust \& Cashman, 2011). Predictions and estimates of $\phi_{\text {cr }}$ are based on percolation theory, experiments, and measurements on natural samples. They range from approximately 30\% to 78\% (Eichelberger et al., 1986 ; Garboczi, Snyder, Douglas, \& Thorpe, 1995 ; Klug \& Cashman, 1996 ; Gaonac'h, Lovejoy, \& Schertzer, 2003 ; Namiki \& Manga, 2008 ; Takeuchi, Tomiya, \& Shinohara, 2009 ; Lindoo, Larsen, Cashman, Dunn, \& Neill, 2016 ; Burgisser et al., 2017 ; Gonnermann et al., 2017).

Almost all samples from rhyolitic Plinian eruptions have porosities in the range $60-90 \%$ and all are permeable (Mueller et al., 2011 ; Colombier et al., 2017 ; Gonnermann et al., 2017). Permeability-porosity of such samples can be fit by a power law with a percolation threshold of approximately 60-70\% (Rust \& Cashman, 2011 ; Nguyen, Gonnermann, \& Houghton, 2014). The lack of low porosity or impermeable Plinian pyroclasts, however, makes it impossible to adequately constrain $\phi_{\text {cr }}$ for Plinian eruptions, allowing for the (C)2019 American Geophysical Union. All Rights Reserved. 
possibility of considerably lower $\phi_{\mathrm{cr}}$. The objective of our study is to provide a frame of reference for interpreting porosity and permeability data from rhyolitic Plinian eruptions. To this end we have analyzed decompression experiments in rhyolitic melt. In the experiments bubbles nucleated and grew under controlled conditions, and we quantified the extent of bubble coalescence as well as the resulting percolation threshold.

\section{Methodology}

\subsection{Overview}

The study involves hydration and decompression experiments, under controlled temperature and pressure, to produce a suite of vesicular rhyolitic samples with a wide range of porosities and bubble number densities. Scanning Electron Microscope (SEM) images of the experimental samples were analyzed to determine porosity, bubble size distribution (BSD), and the percentage of bubbles that are coalesced. Using these data, we performed percolation modeling to estimate connected and percolating porosities. Finally, we compared the experiments with data from Plinian pumices of similar composition.

Our study encompassed the following steps:

1. Decompression experiments. We performed decompression experiments on hydrated, crystal-free rhyolitic melt, resulting in bubble nucleation, growth, and coalescence (Section 2.2.1).

2. Total porosity, Bubble Size Distribution (BSD), and neighbor analysis. After decompression we measured the total porosity, $\phi_{\text {tot }}$, of the experimental samples, which is defined as the volume occupied by all bubbles, divided by the volume of the sample. For the experimental samples $\phi_{\text {tot }}$ was obtained from analysis of two-dimensional SEM images (Section 2.2.2). We confirmed that the porosity and BSD values obtained (C)2019 American Geophysical Union. All Rights Reserved. 
from the SEM image analysis are an adequate approximation of the true three-dimensional porosity by comparing the results from SEM image analysis against porosities obtained from the analysis of three-dimensional micro-tomography data (Appendix A). We also performed a neighbor analysis to estimate the bubble-melt topology of our samples.

3. Coalesced porosity. For the experimental samples, we measured the coalesced porosity, $\phi_{\text {coa }}$, which is defined as the volume occupied by bubbles that are coalesced with at least one of their neighbors (as opposed to isolated bubbles that are entirely surrounded by melt), divided by the total volume of the sample (Figure 1). We refer to the ratio $\phi_{\text {coa }} / \phi_{\text {tot }}$ as the coalesced fraction. As with total porosity, $\phi_{\text {coa }}$ was obtained from the SEM image analysis of the experimental samples. The value of $\phi_{\text {coa }}$ is based on twodimensional image analysis of samples and it can also be calculated through percolation modeling (Section 2.2.3).

4. Percolation modeling and threshold. We performed percolation modeling to obtain the value of $\phi_{\text {coa }}$ together with the corresponding connected porosity, $\phi_{\text {con }}$, and the percolating porosity, $\phi_{\text {per }}$ (Section 2.2.3), both in three dimensions. The connected porosity is the percentage of the sample volume occupied by bubbles that are interconnected and intersect at least one side of the sample, without necessarily crossing the entire sample from side to side (Figure 1). In contrast, the percolating porosity is the volume of interconnected bubbles that span the entire sample from side to side, divided by the total volume of the sample. The percolating porosity remains 0 until the total porosity reaches $\phi_{\mathrm{cr}}$, which is when the sample becomes permeable. Following these definitions, $\phi_{\text {tot }} \geq \phi_{\text {coa }} \geq \phi_{\text {con }} \geq \phi_{\text {per }}$. To determine the percolation threshold, $\phi_{\text {cr }}$, modeled values of $\phi_{\text {tot }}$ and $\phi_{\text {coa }}$ were matched to the measured ones.

(C)2019 American Geophysical Union. All Rights Reserved. 
5. Prior experiments. We re-analyzed data from similar experiments that have been previously published but with significantly longer decompression and/or annealing times and with lower bubble number densities (Section 3.3). We followed the same methodology as for our experiments to obtain values of $\phi_{\mathrm{tot}}, \phi_{\mathrm{coa}}, \phi_{\mathrm{con}}$, and $\phi_{\mathrm{cr}}$.

6. Plinian samples. We compared our results with $\phi_{\text {tot }}$ and $\phi_{\text {con }}$ measured for four samplès suites of rhyolitic Plinian pyroclasts (Section 4.3).

\subsection{Methodological details}

\subsubsection{Hydration and decompression experiments}

The experiments were performed on clear rhyolitic obsidian glass with less than 1 vol.\% Fe-Ti oxide microlites (origin: Millard County, Utah). The composition of the glass was (in wt. $\%$ ): $76.53 \% \mathrm{SiO}_{2}, 0.06 \% \mathrm{TiO}_{2}, 13.01 \% \mathrm{Al}_{2} \mathrm{O}_{3}, 0.79 \% \mathrm{FeO}, 0.08 \% \mathrm{MnO}, 0.02 \%$ $\mathrm{MgO}, 0.74 \% \mathrm{CaO}, 3.87 \% \mathrm{Na}_{2} \mathrm{O}$, and $4.91 \% \mathrm{~K}_{2} \mathrm{O}$, with total Fe reported as $\mathrm{FeO}$. Eleven cores of approximately $2.2 \mathrm{~mm}$ in diameter and $1.1-1.3 \mathrm{~cm}$ in length were drilled from the obsidian and then washed. The glass cores were hydrated at a given pressure and subsets of each core were then rapidly decompressed to lower pressures.

For the hydration experiments, each core was placed in an Au capsule, together with approximately $8 \mathrm{wt} \%$ distilled water. The capsule was crimped, weighed, welded shut, and checked for leaks. Hydrations were carried out in externally heated, cold-seal pressure vessels, made of a Nickel-based alloy. Samples were held at $850 \pm 5{ }^{\circ} \mathrm{C}$ and water-saturated pressures of 190-250 MPa for 6 to 9 days (Table 1). To obtain water content after quenching, a piece of each crystal-free hydrated glass was analyzed by Fourier transform infrared spectroscopy (FTIR) using a Thermo Electron Nicolet 6700 spectrometer and Continuum IR microscope. Three to six spectra were collected, with each spectrum consisting of (C)2019 American Geophysical Union. All Rights Reserved. 
60 scans at a resolution of $4 \mathrm{~cm}^{-1}$, and measured in transmittance mode in the near-IR region (7800-4000 $\left.\mathrm{cm}^{-1}\right)$ with white light and $\mathrm{CaF}_{2}$ beamsplitter. Contents of molecular water and hydroxyl water were determined from absorbances at $5250 \mathrm{~cm}^{-1}$ and 4500 $\mathrm{cm}^{-1}$, respectively, using the model of (Zhang, Jenkins, \& Xu, 1997). Water contents reported in Table 1 are the averaged sums of the two species contents. Hydrated cores had a homogeneous water content ranging from $5.3 \pm 0.1 \mathrm{wt} . \%$ to $6.0 \pm 0.1 \mathrm{wt} . \%$, depending on pressure (Table 1). At a given pressure, measured water contents differ by only $<4 \%$ and are within error of predicted values using the solubility model of (Liu et al., 2005). The remaining part of each hydrated glass was cut into several pieces approximately $5 \mathrm{~mm}$ in length and $2.2 \mathrm{~mm}$ in diameter, allowing for a total of twenty five samples as starting material for the decompression experiments.

For decompression each piece of hydrated glass was placed inside an Au capsule that was welded shut. The capsule was then put into a cup on the end of an Inconel rod and inserted into an externally heated cold-seal pressure vessel fitted with a rapid-quench extension. The sample was held in the water-cooled region of the vessel while the pressure vessel was heated to $850{ }^{\circ} \mathrm{C}\left(875{ }^{\circ} \mathrm{C}\right.$ for sample G-1638). The sample was then inserted into the hot zone of the pressure vessel, once the latter had reached thermal equilibrium. The pressure was quickly adjusted to $1 \mathrm{MPa}$ above the hydration pressure to discourage water loss from the melt during heating. After the sample had been heated for $5 \mathrm{~min}$, pressure was released manually over a time interval of $\tau_{\mathrm{dec}}=1-8 \mathrm{~s}$ to a lower final pressure, $P_{\mathrm{f}}$, in the range 29-123 $\mathrm{MPa}$. The corresponding decompression rates were 21 to 151 $\mathrm{MPa} \mathrm{s}^{-1}$ (Table 2). In all cases an adiabatic temperature drop during decompression corresponds to a solubility difference of $<0.1$ wt.\% (Liu et al., 2005 ; Gonnermann \& (C)2019 American Geophysical Union. All Rights Reserved. 
Gardner, 2013), and the effect on the experimental results is negligible. After a sample had reached its final pressure it was held at that pressure for $\tau_{\mathrm{p}}=6-90 \mathrm{~s}$, giving a total duration of individual experiments of $\tau_{\exp }=\tau_{\text {dec }}+\tau_{\mathrm{p}}=7$ to 92 s. At $\tau_{\exp }$ the sample was quenched rapidly by lowering it back into the water-cooled jacket. A pressure jump of about $3 \mathrm{MPa}$ occurs when the sample holder is replaced with $\mathrm{H}_{2} \mathrm{O}$ in the hot zone during quench. Although this pressure increase may lead to bubble resorption and enrichment of the glass in $\mathrm{H}_{2} \mathrm{O}$ (McIntosh et al., 2014), (Gardner, Hajimirza, Webster, \& Gonnermann, 2018) recently showed that the importance of bubble shrinkage due to this resorption does not significantly affect the porosity measured in our samples. After quenching the capsule was removed from the pressure vessel, checked that it had remained sealed, and the cylinder of porous glass was extracted from the capsule for BSD analysis.

\subsubsection{Image analysis}

We quantified both BSD and melt-bubble topology as they are known to be important features controlling the flow and transport of fluids in porous media, and could affect the value of the percolation threshold (Ioannidis \& Chatzis, 1993 ; Celia, Reeves, \& Ferrand, 1995 ; Vogel, 2002 ; Walsh \& Saar, 2008). Samples were thin-sectioned and grayscale SEM images were taken at a single resolution of 0.91 to 0.09 micron per pixel (corresponding to a magnification of $43 \times$ to $1,500 \times)$, depending on bubble size. One sample was also analyzed using X-ray Computed Tomography to confirm that the 2D methodology yields reasonable results compared to direct 3D results (Appendix A). Analysis was made with a resolution of 4 micron per voxel $\left(1\right.$ voxel $\left.\equiv 1 \mathrm{pixel}^{3}\right)$ at the University of Texas HighResolution X-ray Computed Tomography Facility. Imaging was obtained at $80 \mathrm{kV}, 10 \mathrm{~W}$, and with a 3 s acquisition time, producing a stack of 910 regularly-spaced images.

(C)2019 American Geophysical Union. All Rights Reserved. 
To measure BSD and porosity in 2D, SEM grayscale images were transformed into binary images. Distinction was made between individual bubbles that appeared isolated from one another by glass walls and clusters of two or more bubbles (Figure 2). This distinction allowed for the estimation of the number and volume fraction of bubbles frozen while coalescing at the time of quenching. In addition, broken bubble walls that separated two individual bubbles were redrawn during image analysis (Figure 2). This enabled the estimation of the total number of bubbles that nucleated during decompression, and the visualization of the coalesced bubbles in the form of either 'clusters' or 'individual' bubbles for all the samples.

The area, $A$, of each bubble was then obtained using the Image Processing Toolbox of MATLAB $^{\circledR}$ (Appendix B). Bubbles smaller in area than 20 pixel $^{2}$ were not taken into consideration. They correspond to a porosity below $0.002 \%$ for all the samples and a minimum detectable radius of $0.25-10.1 \mu \mathrm{m}$, depending on the image scale and assuming a spherical shape. The equivalent radius, $R$, of each bubble was then calculated from $A$, assuming the bubble to be spherical. Appendix A shows that the total porosity of the sample equals the area fraction of the bubbles measured in two dimensions, as commonly assumed when bubbles appear spherical and more or less homogeneously distributed. The average BSD of the whole sample was obtained from the four images analyzed for each experimental sample. For each image the bubble number density per volume of melt, $N$, was obtained following the method developed by (Sahagian \& Proussevitch, 1998). Comparison between measurements made in 2D using SEM images and the 'true' 3D data, from microtomography images (Appendix A), shows that the difference in porosity is approximately $1 \%$ and that the relative error in $N$ is approximately $10 \%$ for the 1,210 
bubbles analyzed in 2D. The error in $N$ increases with decreasing number of bubbles analyzed (Sahagian \& Proussevitch, 1998 ; Shea et al., 2010), and we speculate that it is higher than $10 \%$ for samples with less than 100 bubbles analyzed (i.e., G-1592 and G1523). Note that bubble number densities provided in this paper are glass-referenced and correspond to the number density of both isolated and coalesced bubbles. It represents approximately the total number of bubbles that nucleated during the experiment.

\subsubsection{Percolation modeling}

The goal of the percolation modeling was to calculate a percolation threshold for each sample and to determine how this threshold varies with sample porosity, bubble number density, bubble-melt topology, and experimental conditions. Bubbles in the percolation model are represented by spheres that are randomly distributed within a virtual threedimensional cubic volume (Blower, 2001b). The spheres are drawn from a size distribution that is representative of the experimental sample being modeled, and the combined spheres comprise a volume of $\phi_{\text {tot }}$ percent of the virtual sample. Modeling involves the parameter $\varepsilon$, for the amount of overlap between two adjacent spheres. This parameter accounts for the fact that in the percolation model overlapping spheres cannot deform, whereas in reality they may represent bubbles that are not coalesced, because they are deformed and therefore separated from one another by a thin glass wall (Klug \& Cashman, 1996 ; Blower, 2001a ; Giachetti, Druitt, Burgisser, Arbaret, \& Galven, 2010). In the model, if the centers of two spheres of radii $r_{1}$ and $r_{2}$ are separated by a distance less than $(1-\varepsilon) \times\left(r_{1}+r_{2}\right)$, where $0<\varepsilon<1$, then the two spheres are considered coalesced (Blower, 2001a). In contrast, spheres that are separated by a distance ranging between

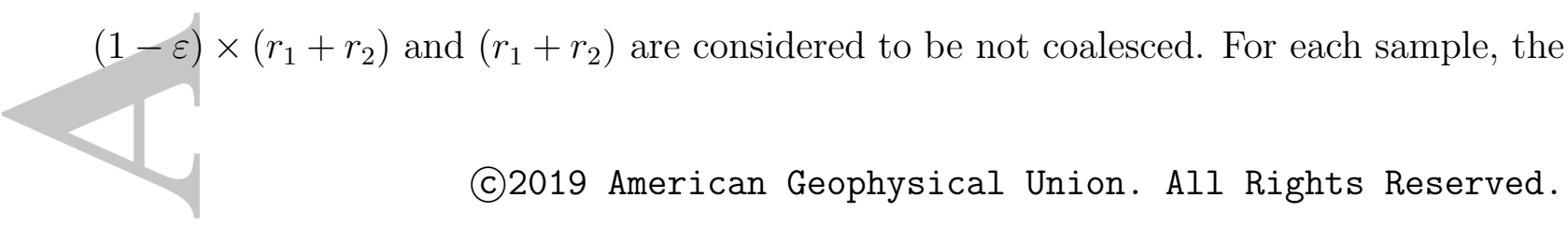


parameter $\varepsilon$ is adjusted so that the percolation model reproduces the measured value of $\phi_{\text {coa }}$

For a given model realization, defined as a random spatial distribution of modeled spheres occupying $\phi_{\text {tot }}$ of the virtual sample, the higher the value of $\varepsilon$ the lower the ratio $\phi_{\text {coa }} / \phi_{\text {tot }}$ (Figures 3 and C2). It is therefore possible to determine which spheres are coalesced and whether they belong to a cluster of coalesced spheres that spans the entire virtual sample, thereby forming a percolating cluster (Sahimi, 1994). For each model realization the percolation model thus allows the calculation of the (two-dimensional) value of $\phi_{\text {coa }}$, as well as the corresponding (three-dimensional) values of $\phi_{\text {con }}$ and $\phi_{\text {per }}$, all of which depend on $\varepsilon$ (Figure C3). Values of $\phi_{\text {coa }}$ and $\phi_{\text {per }}$ were calculated across a wide range of combinations of $\phi_{\text {tot }}$ and $\varepsilon$. Figure 3 a shows that for a given value of $\varepsilon$ all percolation models fall on a single trend when plotted as $\phi_{\text {coa }}$ versus $\phi_{\text {tot }}$, despite the wide range of $N$ and BSD that was used. After trials of different types of equations, we find that this trend can be fitted using the functional relation

$$
\begin{aligned}
& \text { that this trend can be fitted using the functional relation } \\
& \qquad \phi_{\text {coa }}=\phi_{\text {tot }}\left(10^{\alpha}+1\right) e^{\beta e^{\gamma \phi_{\text {tot }} / 100},} \\
& \text { where } \\
& \alpha=-10.41 \varepsilon^{3}+14.44 \varepsilon^{2}-0.15 \varepsilon-2.24, \\
& \text { and } \beta=-1.13 \varepsilon^{2}-4.11 \varepsilon-3.54, \\
& \gamma=-51.15 \varepsilon^{3}+54.67 \varepsilon^{2}-5.24 \varepsilon-6.82 .
\end{aligned}
$$

Because clusters of coalescing bubbles may still be isolated from one another, a high coalesced porosity does not necessarily imply that the sample is permeable. There must be (C)2019 American Geophysical Union. All Rights Reserved. 
at least one percolating cluster. Figure $3 \mathrm{~b}$ shows that for a given value of $\varepsilon$ all percolation models define a single trend of $\phi_{\text {per }}$ as a function of $\phi_{\text {tot }}$. We approximated this functional relation using the empirical equation

$$
\phi_{\mathrm{per}}=\phi_{\mathrm{tot}}+\beta \times\left(1-\left[100 / \phi_{\mathrm{tot}}\right]^{\gamma}\right) \text {, }
$$

where $\beta=5.20 \times 10^{-2} e^{9.14 \varepsilon}, \gamma=4.91+0.69 e^{6.9 \varepsilon}$, and $\phi_{\text {per }}$ and $\phi_{\text {tot }}$ are expressed in $\%$

(Figure 3). Equation 1 is used to determine the value of $\varepsilon$ that reproduces $\phi_{\text {tot }}$ and $\phi_{\text {coa }}$ of the experimental sample, which in turn facilitates the calculation of $\phi_{\text {per }}$. The percolation threshold, $\phi_{\mathrm{cr}}$, for a given value of $\varepsilon$, is then found by solving Equation 2 for $\phi_{\text {per }}=0$. Further details about the percolation modeling are provided in Appendix C.

\section{Results}

\subsection{Current experiments}

Upon decompression bubbles nucleated and grew within the melt, producing quenched samples with a total porosity of $1 \% \leq \phi_{\text {tot }} \leq 74 \%$ (Table 2 ). More than half of the samples have a total porosity that is within $10 \%$ of the expected porosity, based on equilibrium $\mathrm{H}_{2} \mathrm{O}$ solubility and the equation of state for $\mathrm{H}_{2} \mathrm{O}$. One sample, G-1581, has a porosity of $20 \%$ higher than expected, which is difficult to explain. All other samples have a lower than expected porosity (Table 2), presumably because they were still slightly supersaturated in $\mathrm{H}_{2} \mathrm{O}$ upon quenching. Bubble size distributions of all samples are unimodal, indicating a single stage of nucleation and growth (Klug, Cashman, \& Bacon, 2002 ; Shea et al., 2010). Bubble number densities, $N$, vary by more than five orders of magnitude from $6.3 \times 10^{10} \mathrm{~m}^{-3}$ to $2.5 \times 10^{16} \mathrm{~m}^{-3}$. The average bubble radius, assuming a spherical shape,

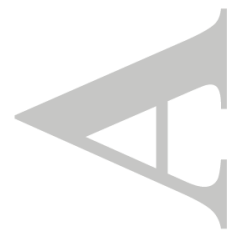

(C)2019 American Geophysical Union. All Rights Reserved. 
is given by

$$
R=\left[\frac{3 \phi_{\text {tot }}}{4 \pi N\left(1-\phi_{\text {tot }}\right)}\right]^{1 / 3}
$$

and ranges between 1.5 and $47.7 \mu \mathrm{m}$ (Table 2). For a given sample the sizes of isolated and coalesced bubbles are not correlated (Figure 4b), which is consistent with data on other experiments and with natural pumices (Giachetti, Burgisser, Arbaret, Druitt, \& Kelfoun, 2011 ; Castro et al., 2012).

The coalesced fraction, $\phi_{\text {coa }} / \phi_{\text {tot }}$, is $0-0.76$. For $\phi_{\text {tot }}>35 \%$ the relationship between $\phi_{\text {tot }}$ and $\phi_{\text {coa }}$ falls within the range $0.35<\varepsilon<0.51$ (Figure 5). The corresponding mean percolation threshold is $\phi_{\mathrm{cr}}=86 \%$, with a range of $73 \%<\phi_{\mathrm{cr}}<91 \%$. In other words, our analysis indicates that none of the experimental samples are permeable, despite high values of $\phi_{\text {tot }}$ and $\phi_{\text {coa }}$.

\subsection{Plinian pumices}

We compare our experimental results with Plinian pumices compiled by (Gonnermann et al., 2017). They include samples from: (1) the explosive phase of the 1060 CE Glass Mountain eruption of Medicine Lake Volcano, California (Heiken, 1978); (2) the 55 ka El Cajete member of Valles Caldera, New Mexico (Self, Kircher, \& Wolff, 1988); (3) Unit 5 of the 181 CE Taupo eruption, New Zealand (Houghton, Carey, \& Rosenberg, 2014); and (4) Episode I of the 1912 eruption of Novarupta, Alaska (Hildreth \& Fierstein, 2012). These fallout pumices were chosen because they are crystal-free to crystal-poor and their matrix glass is rhyolitic with $72<\mathrm{SiO}_{2}<77.8 \mathrm{wt} \%$, similar to our experiments. Taken together, the 127 Plinian pumices have a total porosity of $64-87 \%$ and exhibit a coherent trend of $\phi_{\text {con }}$, measured by helium pycnometry, as a function of $\phi_{\text {tot }}$ (Figure 9$)$. We calculated

$\phi_{\text {con }}$ for each experimental sample using our percolation model and find that the Plinian (C)2019 American Geophysical Union. All Rights Reserved. 
pumices fall on a distinct trend relative to our experimental samples (Figure 9). The Plinian pumices have $0.20<\varepsilon<0.35$ with a percolation threshold of $53 \%<\phi_{\mathrm{cr}}<73 \%$. The percolation thresholds of the Plinian pumices, based on percolation modeling, are broadly consistent with those obtained by fitting permeability data with a power law, and also with the idea that the percolation threshold in expanding silicic magma is high (Rust \& Cashman, 2011 ; Gonnermann et al., 2017).

\subsection{Previous bubble nucleation experiments}

We also compared our experimental results with two suites of experiments published in (Burgisser \& Gardner, 2004) and (Lindoo et al., 2016), which have up to about five orders of magnitude lower bubble number densities (Table 3). Considering the three suites of experiments together extends the range of experimental conditions and sample characteristics over which percolation thresholds can be compared.

The experiments of (Burgisser \& Gardner, 2004) used hydrated rhyolitic melts with 0.1 wt. $\%$ oxides at $825^{\circ} \mathrm{C}$ and decompressed it in three steps: (1) from $155 \mathrm{MPa}$ to $100 \mathrm{MPa}$ in $<1 \mathrm{~s}$, (2) held at $100 \mathrm{MPa}$ for $900 \mathrm{~s}$, and (3) decompressed over 20-3,000 s to a final pressure of 15-60 MPa at which samples were quenched. Samples from (Lindoo et al., 2016) were hydrated crystal-free rhyolitic melts decompressed at $900{ }^{\circ} \mathrm{C}$ over $200-540 \mathrm{~s}$ from 150 $\mathrm{MPa}$ to $15-100 \mathrm{MPa}\left(0.25 \mathrm{MPa} \mathrm{s}^{-1}\right)$ at which they were quenched. All the samples of (Burgisser \& Gardner, 2004) and (Lindoo et al., 2016) had bubble number densities of $10^{10.8}<N<10^{13.5} \mathrm{~m}^{-3}$ (except MC-31 for which $N=10^{15.1} \mathrm{~m}^{-3}$ ), which is two to three orders of magnitude less than most of our samples (Tables 2-3). It should be noted that it

was sometimes impossible to discriminate whether some of the largest isolated bubbles in these experiments were solely formed by nucleation and growth or were the result of the (C)2019 American Geophysical Union. All Rights Reserved. 
coalescence of smaller bubbles followed by viscous relaxation. When encountered, these bubbles were considered isolated and the $\phi_{\text {coa }}$ reported in Table 3 for the most porous experiments should be therefore considered as minimum values.

Identical to our samples, we used percolation modeling to analyze the samples of (Burgisser \& Gardner, 2004) and (Lindoo et al., 2016). We find that $0.21<\varepsilon<0.40$. Relative to our experiments, the combined samples of (Burgisser \& Gardner, 2004) and (Lindoo et al., 2016) delineate a distinct trend of $\phi_{\text {coa }}=f\left(\varepsilon, \phi_{\text {tot }}\right)$ (Figure 6). They also have lower percolation thresholds of $54 \%<\phi_{\mathrm{cr}}<80 \%$, with a mean of $\phi_{\mathrm{cr}}=67 \%$ that is in good agreement with the value of $68 \pm 2 \%$ estimated by (Lindoo et al., 2016) (Figure 6).

\section{Discussion}

In this discussion, we describe the process of bubble coalescence in silicate melts in general and discuss the constraints that the experiments provide on coalescence in rhyolitic magmas.

\subsection{Bubble coalescence in general}

Bubble coalescence occurs during the thinning of inter-bubble melt films. In the absence of large scale shear deformation due to magma flow (Stasiuk et al., 1996 ; Okumura et al., 2006), film thinning involves some combination of bubble growth and melt flow driven by capillary and gravitational forces (Toramaru, 1988 ; Proussevitch, Sahagian, \& Anderson, 1993 ; Navon \& Lyakhovsky, 1998 ; Martula et al., 2000 ; Castro et al., 2012 ; Nguyen et al., 2013). When the thickness of the film that separates two bubbles becomes sufficiently small, the effects of electrostatic repulsive and van der Waals attractive forces become important for the stability of the two gas-liquid interfaces that bound the film. These

(C)2019 American Geophysical Union. All Rights Reserved. 
forces act normal to the interfaces and they are referred to as the disjoining pressure (Derjaguin, Churaev, \& Muller, 1987). It is solely a function of film thickness, and at a film thickness of about $100 \mathrm{~nm}$ it results in film instability and rupture (Qu \& Gouldstone, 2008 ; Kočárková, Rouyer, \& Pigeonneau, 2013 ; Nguyen et al., 2013). Thus, after film thinning, film instability is the second step during bubble coalescence (Aarts \& Lekkerkerker, 2008). The holes formed by film rupture connect adjacent bubbles and the third step in the coalescence process is the growth of these holes, which is a consequence of capillary retraction of the ruptured film. The rate at which the ruptured film retracts is inversely dependent on film viscosity, which can be large for rhyolitic melt, especially at low water content (Hui \& Zhang, 2007). Film retraction may therefore proceed slowly enough for film thinning and rupture to result in a vesicular magma that consists of incompletely coalesced bubbles, defined by the holes within ubiquitously ruptured interbubble films (Eichelberger et al., 1986 ; Klug \& Cashman, 1996 ; Klug et al., 2002 ; Adams, Houghton, Fagents, \& Hildreth, 2006 ; Giachetti et al., 2010 ; Rust \& Cashman, 2011). The resultant interconnected network of bubbles may thus allow for porous flow of the fluid within bubbles, that is the magma may be permeable.

\subsection{Film-thinning mechanisms in the experiments and Plinian eruptions}

In contrast to samples from natural volcanic eruptions, bubbles in all of the analyzed experiments show no evidence for shear deformation due to large scale flow. Of the three remaining processes that result in film thinning - bubble growth, capillary forces, and gravitational forces - the gravitational drainage time scale is considerably longer than the capillary time scale. Gravitational film thinning will therefore not be considered further. The time scale for capillary film drainage, $\tau_{\text {cap }}$, from an initial thickness, $\delta_{0}$, to a final (C)2019 American Geophysical Union. All Rights Reserved. 
thickness, $\delta_{\mathrm{f}}$, at which rupture occurs has been estimated as

$$
\tau_{\text {cap }}=\xi \ln \left(\frac{\delta_{0}}{\delta_{\mathrm{f}}}\right) \frac{\eta R}{\sigma}
$$

Here $\xi=20$ is an empirical constant (Nguyen et al., 2013), $\eta$ is the viscosity of the melt,

$\sigma$ is the surface tension of the bubble, and the average bubble wall thickness can be approximated as $\delta_{0} \sim 2 L$, where

$$
L \sim \frac{1-\phi_{\mathrm{tot}}^{1 / 3}}{\left[N\left(1-\phi_{\mathrm{tot}}\right)\right]^{1 / 3}}
$$

is the half bubble wall thickness (Proussevitch, Sahagian, \& Kutolin, 1993 ; N. Lensky,

Navon, \& Lyakhovsky, 2004). For most experiments $\tau_{\text {cap }}$ is about a factor of 10 to 100 longer than the duration of the experiment. Thus, capillary film drainage was likely not a dominant process during the experiments. By process of elimination we infer that bubble growth must have been the principal process by which bubbles coalesced during the experiments. The same was concluded by (Castro et al., 2012) for Plinian eruptions, although the effect of shear strain, which may enhance bubble coalescence (Okumura et al., 2006 ; Okumura, Nakamura, Nakano, Uesugi, \& Tsuchiyama, 2010 ; Caricchi et al., 2011 ; Okumura, Nakamura, Uesugi, Nakano, \& Fujioka, 2013 ; Gonnermann et al., 2017), was not addressed in that study.

During all experiments the viscous time scale, defined as $\tau_{\eta} \sim \eta /\left(P_{\mathrm{i}}-P_{\mathrm{f}}\right)$, was much smaller than the decompression time, $\tau_{\text {dec }}$, where $\eta$ is the melt viscosity. Consequently, bubble growth was not hindered by viscous forces (Toramaru, 1995 ; Navon, Chekhmir, \& Lyakhovsky, 1998 ; N. Lensky et al., 2004 ; Gonnermann \& Manga, 2007). The characteristic diffusion time is defined as $\tau_{D} \sim L^{2} / D$, where $D$ is $\mathrm{H}_{2} \mathrm{O}$ diffusivity, and $L$ is the characteristic diffusion length. Values of $\tau_{D}$ range between $\sim 10^{-1} \mathrm{~s}$ for our (C)2019 American Geophysical Union. All Rights Reserved. 
experiments and $10^{1} \mathrm{~s}$ to $10^{3} \mathrm{~s}$ for those of (Burgisser \& Gardner, 2004) or (Lindoo et al., 2016). Thus, for all experiments $\tau_{D}<\tau_{\text {exp }}$, meaning bubble growth was not limited by diffusion of water into bubbles. Because both $\tau_{D}$ and $\tau_{\eta}$ are smaller than $\tau_{\exp }$ bubble growth was not rate-limited during decompression and there was no significant bubble growth during the annealing period of the experiments.

\subsection{Percolation threshold}

In the subsequent paragraphs we investigate the processes and properties that affect bubble coalescence and the value of the percolation threshold in the experiments and Plinian samples.

\subsubsection{Experiments}

We have shown that the value of the percolation threshold varies from $50-80 \%$ for the low- $N$ experiments, published in (Burgisser \& Gardner, 2004) and (Lindoo et al., 2016), to $80-90 \%$ for our high- $N$ experiments. Correspondingly, at any given $\phi_{\text {tot }}$, the coalesced fraction is higher in the low- $N$ experiments. Based on scaling analysis, bubble growth during the experiments was not rate limited and capillary or gravitational film drainage were too slow to have significantly affected coalescence. Therefore, coalescence must have been primarily associated with film thinning due to bubble growth during decompression. Furthermore, there are no systematic relationships between $\phi_{\mathrm{cr}}$ and other parameters (e.g., decompression rate, amount of pressure drop) to indicate that vesiculation dynamics account for the differences in $\phi_{\text {cr }}$ between the experimental suites. Instead, we observe a broad correlation between $\phi_{\text {cr }}$ and $N$, as well as between $\phi_{\text {cr }}$ and the mode of coordination numbers, $n_{\mathrm{c}}$, and the index of system disorder, $\omega$ (Figure 7). These correlations suggest that differences in $\phi_{\mathrm{cr}}$ are primarily the consequence of structural arrangements of bubbles.

(C)2019 American Geophysical Union. All Rights Reserved. 
In our experiments about $10^{14}$ to $10^{16}$ bubbles nucleated per $\mathrm{m}^{3}$ melt (Table 2), and about $10^{12}$ to $10^{12.5} \mathrm{~m}^{-3}$ in the experiments of (Burgisser \& Gardner, 2004). Both experimental suites have unimodal bubble size distributions (Burgisser \& Gardner, 2004). At similar $\phi_{\text {tot }}$ bubble size distributions with lower $N$ are shifted to larger sizes. Thus, bubbles in low- $N$ experiments grew to larger size than in high- $N$ experiments, implying that inter-bubble melt films underwent larger strains in low- $N$ experiments.

We also measured the distribution of coordination numbers, $f\left(n_{\mathrm{c}}\right)$, for samples from our experiments and those of (Burgisser \& Gardner, 2004). Conceptually, the coordination number is obtained by tessellation, whereby the space associated with each bubble is represented by a polyhedral cell. The coordination number represents the number of cell edges connected to a particular cell vertex. It is therefore a topological property of the bubble-melt structure. $f\left(n_{\mathrm{c}}\right)$ was calculated using the Neighbor Analysis macro and Voronoi option of the BioVoxxel Toolbox in ImageJ (Brocher, 2014). In addition we calculated the ratio $\omega=f(5) / f(6)$, where $\omega \gtrsim 1$ indicate a more disordered state than values of $\omega<1$ (Glazier, Anderson, \& Grest, 1990 ; Cashman \& Mangan, 1994). The low$N$ experiments of (Burgisser \& Gardner, 2004) have a broader distribution of coordination numbers with a lower mode (3.6 to 5.6, average of 5.0, Figure 8a-c) and a higher degree of structure disorder $(1.0<\omega<1.8$, average of 1.32, Figure $8 \mathrm{~d})$ compared to our samples with $N>10^{14} \mathrm{~m}^{-3}$ (mode at 5.3 to 5.8 with an average of 5.6 , and $0.8<\omega<1$ with an average of 0.95 ). Our four experiments with $N<10^{13} \mathrm{~m}^{-3}$, and sufficient bubbles to be analyzed, also have a lower mode (4.4-5.5) and a higher index of system disorder $(1.0<\omega<1.2)$, suggesting that these correlations are not due to experimental bias. Overall we find that bubble number density and disorder of bubble-melt structure are anti-correlated. The (C)2019 American Geophysical Union. All Rights Reserved. 
higher structural disorder of the low- $N$ samples appears to translate into higher values of $\phi_{\text {coa }}$ and lower $\phi_{\mathrm{cr}}$.

\subsubsection{Plinian samples}

The Plinian samples have bubble size distributions that range from uni-modal to multimodal with bubble that span at least 2-3 orders of magnitude in size (Adams et al., 2006 ; Houghton et al., 2010 ; Rust \& Cashman, 2011 ; Gonnermann et al., 2017). Typical Plinian pumices from Medicine Lake (this study) and Taupo (Houghton et al., 2010) have also coordination number distributions with a lower mode (4.5 to 5.2) and a higher index of system disorder $(1.1<\omega<1.8)$ than our experiments with similar $N$ (Figure 8a). In addition, elongated vesicles due to shear deformation are abundant in the Plinian samples (Klug \& Cashman, 1996 ; Gardner, Thomas, Jaupart, \& Tait, 1996 ; Klug et al., 2002 ; Adams et al., 2006 ; Rust \& Cashman, 2011). Torsional deformation experiments on vesicular silicic melts have demonstrated that shear deformation enhances bubble coalescence (Okumura et al., 2006, 2010 ; Caricchi et al., 2011 ; Okumura et al., 2013 ; Gonnermann et al., 2017) and reduce the percolation threshold (Garboczi et al., 1995). We surmise that the comparatively lower percolation threshold of Plinian samples may be attributed to a higher degree of structural disorder compared to our experimental samples with similar bubble number densities, as well as shear deformation.

\section{Conclusions}

We performed decompression experiments on a crystal-free rhyolitic melt to characterize

bubble coalescence and to determine the percolation threshold of expanding magmas under known vesiculation conditions. Samples decompressed at 20-150 $\mathrm{MPa} \mathrm{s}^{-1}$ had a uni-modal size distribution of bubbles and total porosities of 1-74\%. The samples (C)2019 American Geophysical Union. All Rights Reserved. 
porosity is comprised by $0-76 \%$ of coalesced bubbles. Coalesced and total porosities are positively correlated and percolation modeling predicts a percolation threshold of $86 \%$. Similar experiments with lower bubble number densities exhibit a similar correlation, but with a systematically higher coalescence fraction at any given total porosity, resulting a percolation threshold of $67 \%$. The experimental samples have a percolation threshold that is positively correlated with the bubble number density and negatively with the index of packing disorder. Because capillary and gravitational film drainage were likely insignificant, film thinning due to bubble growth was the most likely driver for coalescence, with percolation threshold a consequence of the structural characteristics of the bubblemelt system.

Plinian pumices are consistent with a percolation threshold of about $60 \%$, which is distinctly lower than for our experimental samples with similar bubble number densities. Bubbles in the Plinian samples have wider size distributions and higher structural disorder than in the experiments. Plinian samples also show abundant evidence for shear deformation. The lower percolation threshold of the Plinian samples, relative to our experimental samples with similar bubble number densities, is likely a consequence of enhanced coalescence due to shear deformation of the erupting magma, as well as their in inherently greater structural complexity resulting from a more complex nucleation process.

Acknowledgments. This material is based upon work supported by the National Science Foundation under grants EAR-1250451 and EAR-1348050. Any opinions, findings, and conclusions or recommendations expressed in this material are those of the authors and do not necessarily reflect the views of the National Science Foundation. The authors thank Marie Edmonds for the efficient editorial handling of the manuscript, as well as the (C)2019 American Geophysical Union. All Rights Reserved. 
three anonymous reviewers for thoughtful reviews that helped improve the manuscript. The authors also thank Amanda Lindoo and Jessica Larsen for having provided the original optical images that helped discuss our results further. The data used are listed in the references, tables, and appendices.

\section{Appendix A: Validation of image analysis methodology using microtomography}

Sample G-1484 was analyzed by microtomography $(\mu \mathrm{CT})$ at the University of Texas High-Resolution X-ray Computed Tomography Facility. Only one sample was analyzed using this technique because quantitative treatment of coalesced bubbles in three dimensions is challenging (Giachetti et al., 2011). Four slices were randomly chosen inside the

stack of 910 images and analyzed in 2D using the methodology detailed in Section 2.2.2. The results were used to demonstrate that data obtained in $2 \mathrm{D}$ by image analysis are representative of the 'true' $3 \mathrm{D}$ data.

Original grayscale $\mu \mathrm{CT}$ images were binarized using the image processing package Fiji (Schindelin et al., 2012). Because data were acquired at a resolution of $4 \mu \mathrm{m} /$ voxel, adjacent bubbles at a distance of $\leq 4 \mu \mathrm{m}$ may appear isolated from one another on the grayscale images but become artificially coalesced after the binarization process because at least one voxel was misinterpreted as void instead of glass (red rectangles in Figure A1a-b). These bubbles were successfully 'de-coalesced' using the Distance Transform Watershed 3D filter of the MorphoLibJ library in Fiji (Legland, Arganda-Carreras, \& Andrey, 2016). This filter also allowed actual coalesced bubbles to remain intact (green rectangles in Figure A1c), therefore preserving the coalesced porosity of the sample. The volume, center of mass, and the inertia ellipsoid were calculated for each of the 6,518 objects present in the image stack using the 'Particle Analysis 3D' module of the MorphoLibJ library (Legland (C)2019 American Geophysical Union. All Rights Reserved. 
et al., 2016). Two groups emerged when plotting the sphericity of the bubbles, $\Psi$, as a function of their aspect ratio, $L_{a} / L_{b}$ (Figure A2a). Bubbles with $\Psi<0.88$ and $L_{a} / L_{b}>1.5$ are clusters of coalesced bubbles while isolated bubbles have $\Psi=0.95 \pm 0.03$, as confirmed by a 3D rendering (Figure A2b). We found three-dimensional total and connected porosities of $33.5 \%$ and $0.7 \%$, respectively, which is similar to the values of $33.1 \%$ and $0.9 \%$ found from SEM image analysis (see Table 2). Assuming each cluster of coalesced bubbles in the $\mu \mathrm{CT}$ images was made of two individual bubbles, we obtained a total number density of individual bubbles of $\log (N)=12.42$ in $3 \mathrm{D}$, compared to $\log (N)=12.38$ obtained in 2D, These results demonstrate the robustness of the procedure used to analyze the SEM images in (Section 2.2.2), even at low porosity and low bubble number density.

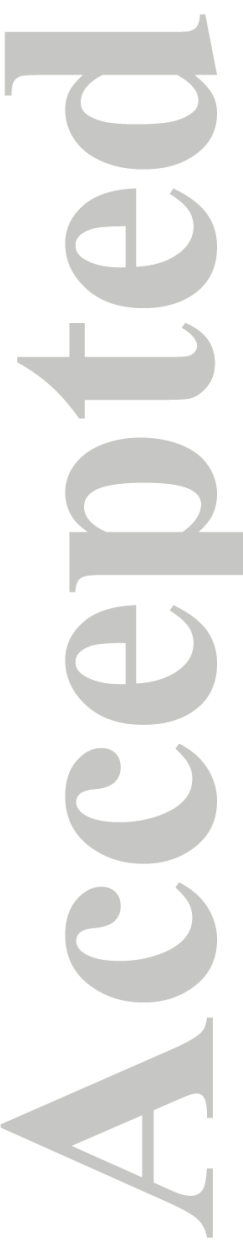

(C)2019 American Geophysical Union. All Rights Reserved. 


\section{Appendix B: Bubbles cut by edge of image}

For bubbles that were cut by the edge of the SEM image (Figures 2 and B1) the equivalent radius was calculated as

$$
R=\frac{W}{2}+\frac{L^{2}}{8 W}
$$

Here $L$ and $W$ are the length and width of the rectangle bounding the cut bubble, respectively (Figure B1). Each of the cut bubbles was counted as $n=1$ for a bubble located totally inside the image, and $0<n<1$ if the bubble was cut by the edge of the image, where $n=A /\left(\pi R^{2}\right)$.
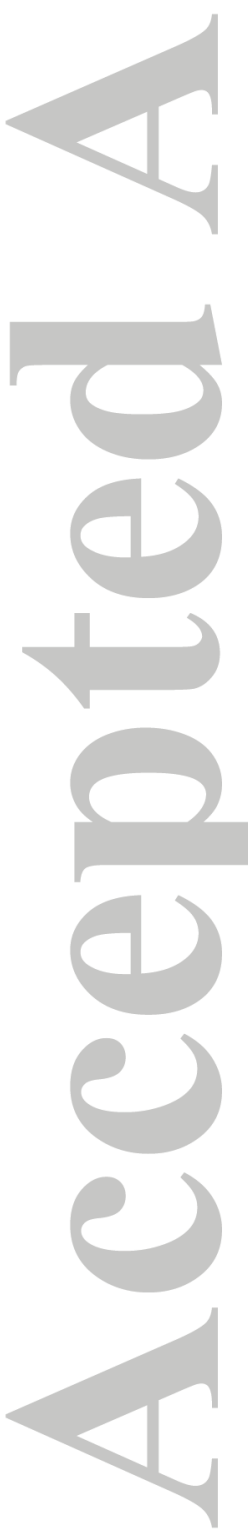

(C)2019 American Geophysical Union. All Rights Reserved. 


\section{Appendix C: Percolation modeling}

\section{C1. Methodology}

The percolation model randomly distributes spheres within a three-dimensional cubic volume (Blower, 2001b ; Gonnermann et al., 2017). Spheres are drawn from the BSD that is representative of the given sample. The virtual cube side is at least ten times larger than the radius of the largest bubble in the sample, ensuring a statistically valid population distribution (Blower, 2001b). A new spatial distribution of spheres is produced each time the model is run. The number of spheres placed in the domain is therefore adjusted so that the modeled total porosity and number density of spheres (in $\log _{10}$ ) both fall within $5 \%$ of the sample (Table 1). One distribution of spheres was obtained for each sample by setting a $90^{3}$ to $3,000^{3}-\mu \mathrm{m}^{3}$ cubic domain and $765-33,130$ spheres, depending on the maximum bubble size and BSD of the sample.

Because the spheres are randomly placed inside the virtual domain they may partly overlap. If the centers of two spheres of radii $r_{1}$ and $r_{2}$ are separated by a distance less than $(1-\varepsilon) \times\left(r_{1}+r_{2}\right)$, where $0 \leq \varepsilon \leq 1$, the two spheres are considered coalesced (Blower, 2001a ; Gonnermann et al., 2017). For each distribution, $\varepsilon$ was varied from 0 to 0.5 in increments of 0.05 , producing eleven cases per sample. An additional series of 64 distributions were produced to cover a wider range of total porosities by using the BSD of sample G-1466 and by varying the total number of bubbles from 1,613 to 51,123. For each case, the model calculates the total porosity, $\phi_{\text {tot }}$, the connected porosity, $\phi_{\text {con }}$, and the percolating porosity, $\phi_{\text {per }}$, all in three dimensions. It also calculates the coalesced porosity

in two dimensions, $\phi_{\text {coa }}$, for 50 random planes cut inside each virtual cube and analyzed

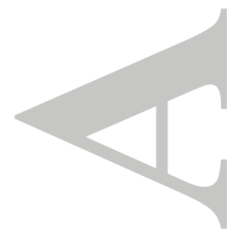

(C)2019 American Geophysical Union. All Rights Reserved. 
as described in Section 2.2.2, to be compared directly with the $\phi_{\text {coa }}$ of the experimental samples obtained by analysis of the SEM images.

\section{C2. Coalesced porosity in $2 \mathrm{D}$ and $3 \mathrm{D}$}

Two bubbles may appear isolated from one another in an SEM image or in a random plane traced through the percolation model, even though they are actually coalesced in the third dimension (Figure C1a). As a consequence, the coalesced porosity obtained from SEM image or virtual slice analysis may underestimate the true coalesced porosity in three dimensions. To evaluate the importance of this bias, we used the results of the model and compared the coalesced porosity obtained in 2D by analysis of 50 random planes cut inside each virtual cube, $\phi_{\mathrm{coa}_{2 \mathrm{D}}}$, with the true coalesced porosity calculated by the model in three dimensions, $\phi_{\mathrm{coa}_{3 \mathrm{D}}}$. The results show that average $\phi_{\mathrm{coa}_{2 \mathrm{D}}}$ can be up to two times lower than $\phi_{\text {coa3D }}$, but this discrepancy decreases with increasing total porosity, and it is always $<10 \%$ for $\phi_{\text {tot }}>50 \%$ (Figure C1b). Furthermore, $\phi_{\mathrm{coa}_{2 \mathrm{D}}} \approx \phi_{\mathrm{coa}_{3 \mathrm{D}}}$ for $\varepsilon \gtrsim$ 0.3 at any given $\phi_{\text {tot }}$, which is the case of almost all the samples analyzed in this study.

\section{C3. Finding $\varepsilon$ and calculating the percolation threshold}

At a given $\phi_{\text {tot }}$ in the model, increasing $\varepsilon$ has for consequence to decrease $\phi_{\text {coa }}, \phi_{\text {con }}$, and $\phi_{\text {per }}$ (Figures C2, C3). For each experiment the value of $\varepsilon$ for which the modeled $\phi_{\text {coa }}$ matches that measured by SEM image analysis of the sample (both in 2D) was found using an interpolation of the modeled $\phi_{\text {coa }}$ over $0<\varepsilon<0.5$ (Figure C3). Using interpolations over

$0<\varepsilon<0.5$ we then also calculated $\phi_{\text {con }}$ and $\phi_{\text {per }}$ for the value of $\varepsilon$ previously found (Figure $\mathrm{C} 3)$. Finally, the percolation threshold, $\phi_{\mathrm{cr}}$, for a given value of $\varepsilon$, is found by solving Equation 2 for $\phi_{\text {per }}=0$.

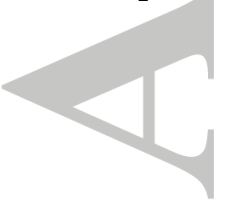

(C)2019 American Geophysical Union. All Rights Reserved. 


\section{Références}

Aarts, D. G., \& Lekkerkerker, H. N. (2008). Droplet coalescence: drainage, film rupture and neck growth in ultralow interfacial tension systems. Journal of fluid mechanics, 606, $275-294$.

Adams, N., Houghton, B., Fagents, S., \& Hildreth, W. (2006). The transition from explosive to effusive eruptive regime: The example of the 1912 Novarupta eruption, Alaska. Geol. Soc. Amer. Bull., 118, 620-634. 10.1007/s00445-006-0067-4

Alidibirov, M. (1994). A model for viscous magma fragmentation during volcanic blasts. Bull. Volcanol., 56, 459-465.

Blower, J. D. (2001a). Factors controlling permeability - porosity relationships in magma. Bull. Volcanol., 63, 497-504. 10.1007/s004450100172

Blower, J. D. (2001b). A three-dimensional network model of permeability in vesicular material. Comput. Geosci., 27, 115-119. 10.1016/S0098-3004(00)00066-2

Brocher, J. (2014). Qualitative and quantitative evaluation of two new histogram limiting binarization algorithms. International Journal of Image Processing (IJIP), $\underline{8}(2), 30$.

Burgisser, A., Chevalier, L., Gardner, J. E., \& Castro, J. M. (2017). The percolation threshold and permeability evolution of ascending magmas. Earth and Planetary Science Letters, $\underline{470}, 37-47$.

Burgisser, A., \& Gardner, J. (2004). Experimental constraints on degassing and permeability in volcanic conduit flow. Bull. Volcanol., 67, 42-56. 10.1007/s00445-004$0359-5$

Caricchi, L., Pommier, A., Pistone, M., Castro, J., Burgisser, A., \& Perugini, D. (2011). Strain-induced magma degassing: insights from simple-shear experiments on bubble (C)2019 American Geophysical Union. All Rights Reserved. 
bearing melts. Bulletin of volcanology, 73(9), 1245-1257.

Cashman, K. V., \& Mangan, M. T. (1994). Physical aspects of magmatic degassing; , constraints on vesiculation processes from textural studies of eruptive products. Reviews in Mineralogy and Geochemistry, 30(1), 447-478.

Castro, J. M., Burgisser, A., Schipper, C. I., \& Mancini, S. (2012). Mechanisms of bubble coalescence in silicic magmas. Bull. Volcanol., 74, 2339-2352. 10.1007/s00445-0120666-1

Celia, M. A., Reeves, P. C., \& Ferrand, L. A. (1995). Recent advances in pore scale models for multiphase flow in porous media. Reviews of Geophysics, 33(S2), 1049 1057.

Colombier, M., Wadsworth, F. B., Gurioli, L., Scheu, B., Kueppers, U., Di Muro, A., \& Dingwell, D. B. (2017). The evolution of pore connectivity in volcanic rocks. Earth and Planetary Science Letters, 462, 99-109.

Degruyter, W., Bachmann, O., Burgisser, A., \& Manga, M. (2012). The effects of outgassing on the transition between effusive and explosive silicic eruptions. Earth Planet. Sci. Lett., 349-350, 161-170. 10.1016/j.epsl.2012.06.056

Derjaguin, B., Churaev, N., \& Muller, V. (1987). Wetting films. In Surface forces (pp. 327-367). Springer.

Dingwell, D. B. (1996). Volcanic Dilemma-Flow or Blow? Science, 5278, 1054-1055. 10.1126/science.273.5278.1054

Eichelberger, J. C., Carrigan, C. R., Westrich, H. R., \& Price, R. H. (1986). Non-explosive silicic volcanism. Nature, $\underline{323}$, 598-602. 10.1038/323598a0

Gaonac'h, H., Lovejoy, S., \& Schertzer, D. (2003). Percolating magmas and explosive (C)2019 American Geophysical Union. All Rights Reserved. 
volcanism. Geophysical research letters, 30(11).

Garboczi, E., Snyder, K., Douglas, J., \& Thorpe, M. (1995). Geometrical percolation threshold of overlapping ellipsoids. Physical review E, 52(1), 819.

Gardner, J. E. (2007). Bubble coalescence in rhyolitic melts during decompression from high pressure. J. Volcanol. Geotherm. Res., 166, 161-176.

Gardner, J. E., Hajimirza, S., Webster, J. D., \& Gonnermann, H. M. (2018). The impact of dissolved fluorine on bubble nucleation in hydrous rhyolite melts. Geochimica et Cosmochimica Acta, 226, 174-181.

Gardner, J. E., Thomas, R. M. E., Jaupart, C., \& Tait, S. (1996). Fragmentation of magma during Plinian volcanic eruptions. Bull. Volcanol., 58, 144-162.

Giachetti, T., Burgisser, A., Arbaret, L., Druitt, T. H., \& Kelfoun, K. (2011). Quantitative textural analysis of Vulcanian pyroclasts (Montserrat) using multi-scale X-ray computed microtomography: compared with results from 2D image analysis. Bull. $\underline{\text { Volcanol., }} \underline{73}$, 1295-1309. 10.1007/s00445-011-0472-1

Giachetti, T., Druitt, T. H., Burgisser, A., Arbaret, L., \& Galven, C. (2010). Bubble nucleation, growth and coalescence during the 1997 vulcanian explosions of soufrière hills volcano, montserrat. Journal of Volcanology and Geothermal Research, 193(3), $215-231$.

Glazier, J. A., Anderson, M. P., \& Grest, G. S. (1990). Coarsening in the two-dimensional soap froth and the large-Q potts model: a detailed comparison. $\underline{\text { Philosophical }}$ $\underline{\text { Magazine B }}, \underline{62}(6), 615-645$.

Gonnermann, H. M. (2015). Magma fragmentation. Annual Review of Earth and $+$ $\underline{\text { Planetary Sciences, }} \underline{43}(1)$. 
Gonnermann, H. M., \& Gardner, J. E. (2013). Homogeneous bubble nucleation in rhyolitic melt: Experiments and nonclassical theory. Geochem. Geophys. Geosyst., 14, 4758-4773. 10.1002/ggge.20281

Gonnermann, H. M., Giachetti, T., Fliedner, C., Nguyen, C. T., Houghton, B. F., Crozier, J. A., \& Carey, R. J. (2017). Permeability during magma expansion and compaction: Observations and experiments. Journal of Geophysical Research: Solid Earth, 122. 10.1002/2017JB014783

Gonnermann, H. M., \& Manga, M. (2007). The fluid mechanics inside a volcano. Annu.

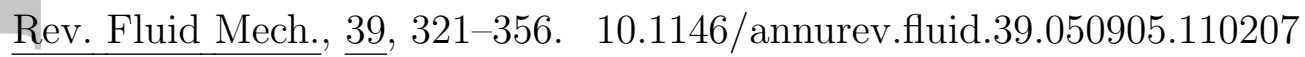

Heap, M. J., \& Kennedy, B. M. (2016). Exploring the scale-dependent permeability of fractured andesite. Earth and Planetary Science Letters, 447, 139-150.

Heiken, G. (1978). Plinian-type eruptions in the Medicine Lake Highland, California, and the nature of the underlying magma. J. Volcanol. Geotherm. Res., 4, 375-402. 10.1016/0377-0273(78)90023-9

Hildreth, W., \& Fierstein, J. (2012). The Novarupta-Katmai eruption of 1912? Largest eruption of the twentieth century. Centennial perspectives: U.S. Geological Survey Professional Paper, 1791, 278 pp.

Houghton, B., Carey, R., Cashman, K., Wilson, C., Hobden, B. J., \& Hammer, J. (2010). Diverse patterns of ascent, degassing, and eruption of rhyolite magma during the 1.8 ka taupo eruption, new zealand: evidence from clast vesicularity. Journal of Volcanology and Geothermal Research, 195(1), 31-47.

Houghton, B., Carey, R., \& Rosenberg, M. (2014). The 1800a taupo eruption: "iii wind" blows the ultraplinian type event down to plinian. Geology, 42(5), 459-461.

(C)2019 American Geophysical Union. All Rights Reserved. 
Hui, H., \& Zhang, Y. (2007). Toward a general viscosity equation for natural anhydrous and hydrous silicate melts. Geochim. Cosmochim. Acta, 71, 403-416.

10.1016/j.gca.2006.09.003

Ioannidis, M. A., \& Chatzis, I. (1993). Network modelling of pore structure and transport properties of porous media. Chemical Engineering Science, 48(5), 951-972.

Jaupart, C., \& Allègre, C. J. (1991). Gas content, eruption rate and instabilities of eruption regime in silicic volcanoes. Earth Planet. Sci. Lett., 102, 413-429. 10.1016/0012821X(91)90032-D

Kerrick, D. M., \& Jacobs, G. K. (1981). A modified Redlich-Kwong equation for $\mathrm{H}_{2} \mathrm{O}$, $\mathrm{CO}_{2}$ and $\mathrm{H}_{2} \mathrm{O}-\mathrm{CO}_{2}$ mixtures at elevated pressures and temperatures. Am. J. Sci., 281, $735-767$.

Klug, C., \& Cashman, K. V. (1996). Permeability development in vesiculating magmas: implications for fragmentation. Bull. Volcanol., 58, 87-100. 10.1007/s004450050128

Klug, C., Cashman, K. V., \& Bacon, C. R. (2002). Structure and physical characteristics of pumice from climatic eruption of Mt. Mazama (Crater Lake), Oregon. Bull. Volcanol., 64, 486 - 501. 10.1007/s00445-002-0230-5

Kočárková, H., Rouyer, F., \& Pigeonneau, F. (2013). Film drainage of viscous liquid on top of bare bubble: Influence of the bond number. Physics of Fluids (1994-present), $\underline{25}(2), 022105$.

Kushnir, A. R., Martel, C., Champallier, R., \& Arbaret, L. (2017). In situ confirmation of permeability development in shearing bubble-bearing melts and implications for volcanic outgassing. Earth and Planetary Science Letters, 458, 315-326.

Lange, R. A. (1994). The effect of $\mathrm{H}_{2} \mathrm{O}, \mathrm{CO}_{2}$ and $\mathrm{F}$ on the density and viscosity of (C)2019 American Geophysical Union. All Rights Reserved. 
silicate melts. Reviews in Mineralogy and Geochemistry, 30(1), 331-369.

Lavallée, Y., Benson, P. M., Heap, M. J., Hess, K.-U., Flaws, A., Schillinger, B.Dingwell, D. B. (2013). Reconstructing magma failure and the degassing network of domebuilding eruptions. Geology, 41(4), 515-518. 10.1130/G33948.1

Legland, D., Arganda-Carreras, I., \& Andrey, P. (2016). Morpholibj: integrated library and plugins for mathematical morphology with imagej. Bioinformatics, 32(22), 35323534.

Lensky, N., Navon, O., \& Lyakhovsky, V. (2004). Bubble growth during decompression of magma: experimental and theoretical investigation. Journal of Volcanology and Geothermal Research, 129(1), 7-22. doi:10.1016/S0377-0273(03)00229-4

Lensky, N. G., Lyakhovsky, V., \& Navon, O. (2001). Radial variations of melt viscosity around growing bubbles and gas overpressure in vesiculating magmas. Earth. Planet. Sci. Lett., 186, 1-6. 10.1016/S0012-821X(01)00227-8

Lindoo, A., Larsen, J., Cashman, K., Dunn, A., \& Neill, O. (2016). An experimental study of permeability development as a function of crystal-free melt viscosity. Earth $\underline{\text { and Planetary Science Letters, }} \underline{435}, 45-54$.

Liu, Y., Zhang, Y., \& Behrens, H. (2005). Solubility of $\mathrm{H}_{2} \mathrm{O}$ in rhyolitic melts at low pressures and a new empirical model for mixed $\mathrm{H}_{2} \mathrm{O}-\mathrm{CO}_{2}$ solubility in rhyolitic melts. J. Volcanol. Geotherm. Res., 143, 219-235. 10.1016/j.jvolgeores.2004.09.019

Martel, C., \& Iacono-Marziano, G. (2015). Timescales of bubble coalescence, outgassing, and foam collapse in decompressed rhyolitic melts. Earth and Planetary Science Letters, $\underline{412}, 173-185$.

Martula, D. S., Hasegawa, T., Lloyd, D. R., \& Bonnecaze, R. T. (2000). Coalescence(C)2019 American Geophysical Union. All Rights Reserved. 
induced coalescence of inviscid droplets in a viscous fluid. Journal of colloid and interface science, $\underline{232}(2), 241-253$.

McBirney, A. R., \& Murase, T. (1970). Factors governing the formation of pyroclastic rocks. Bull. Volcanol., 34, 372-384. 10.1007/BF02596762

McIntosh, I. M., W., L. E., Humphreys, M. C. S., Nichols, A. R. L., Burgisser, A., Schipper, C. I., \& Larsen, J. F. (2014). Distribution of dissolved water in magmatic glass records growth and resorption of bubbles. Earth Planet. Sci. Lett., $\underline{401}$, 1-11. 10.1016/j.epsl.2014.05.037

Mueller, S., Scheu, B., Kueppers, U., Spieler, O., Richard, D., \& Dingwell, D. B. (2011). The porosity of pryoclasts as an indicator of volcanic explosivity. J. Volcanol. Geortherm. Res., 203, 168-174. 10.1016/j.jvolgeores.2011.04.006

Mueller, S., Scheu, B., Spieler, O., \& Dingwell, D. B. (2008). Permeability control on magma fragmentation. Geology, 36, 399-402. 10.1130/G24605A.1

Namiki, A., \& Manga, M. (2008). Transition between fragmentation and permeable outgassing of low viscosity magmas. J. Volcanol. Geotherm. Res., 169, 48-60. 10.1016/j.jvolgeores.2007.07.020

Navon, O., Chekhmir, A., \& Lyakhovsky, V. (1998). Bubble growth in highly viscous melts: theory, experiments, and autoexplosivity of dome lavas. Earth Planet. Sci. Lett., 160, 763-776.

Navon, O., \& Lyakhovsky, V. (1998). Vesiculation processes in silicic magmas. Geological Society, London, Special Publications, 145(1), 27-50.

Nguyen, C. T., Gonnermann, H. M., Chen, Y., Huber, C., Maiorano, A. A., Gouldstone, A., \& Dufek, J. (2013). Film drainage and the lifetime of bubbles. Geochem. (C)2019 American Geophysical Union. All Rights Reserved. 
Geophys. Geosyst., 14, 3616-3631. 10.1002/ggge.20198

Nguyen, C. T., Gonnermann, H. M., \& Houghton, B. F. (2014). Explosive to effusive transition during the largest volcanic eruption of the 20th century (Novarupta 1912, Alaska). Geology. 10.1130/G35593.1

Okumura, S., Nakamura, M., Nakano, T., Uesugi, K., \& Tsuchiyama, A. (2010). Shear deformation experiments on vesicular rhyolite: Implications for brittle fracturing, degassing, and compaction of magmas in volcanic conduits. J. Geophys. Res.: Solid $\underline{\text { Earth, }} \underline{115}(\mathrm{~B} 6) . \quad 10.1029 / 2009 J B 006904$

Okumura, S., Nakamura, M., \& Tsuchiyama, A. (2006). Shear-induced bubble coalescence in rhyolitic melts with low vesicularity. Geophysical research letters, 33(20).

Okumura, S., Nakamura, M., Uesugi, K., Nakano, T., \& Fujioka, T. (2013). Coupled effect of magma degassing and rheology on silicic volcanism. Earth Planet. Sci. Lett., 362, 163-170. 10.1016/j.epsl.2012.11.056

Proussevitch, A. A., Sahagian, D. L., \& Anderson, A. T. (1993). Dynamics of diffusive bubble growth in magmas: Isothermal case. J. Geophys. Res., 98, 22,283-22,307. 10.1029/93JB02027

Proussevitch, A. A., Sahagian, D. L., \& Kutolin, V. A. (1993). Stability of foams in silicate melts. Journal of Volcanology and Geothermal Research, 59(1-2), 161-178.

Qu, M., \& Gouldstone, A. (2008). On the role of bubbles in metallic splat nanopores and adhesion. Journal of thermal spray technology, 17(4), 486-494.

Rust, A. C., \& Cashman, K. V. (2011). Permeability controls on expansion and size distributions of pyroclasts. J. Geophys. Res., 116, B11202. 10.1029/2011JB008494 Saar, M., \& Manga, M. (1999). Permeability - porosity relationship in vesicular basalts. (C)2019 American Geophysical Union. All Rights Reserved. 
Geophys. Res. Lett., 26, 111-114. 10.1029/1998GL900256

Sahagian, D. L., \& Proussevitch, A. A. (1998). 3D particle size distributions from 2D observations: stereology for natural applications. Journal of Volcanology and Geothermal Research, 84(3), 173-196. 10.1016/S0377-0273(98)00043-2

Sahimi, M. (1994). Applications of Percolation Theory. London : Taylor and Francis.

Schindelin, J., Arganda-Carreras, I., Frise, E., Kaynig, V., Longair, M., Pietzsch, T.others (2012). Fiji: an open-source platform for biological-image analysis. Nature methods, $\underline{9}(7), 676$.

Self, S., Kircher, D., \& Wolff, J. (1988). The E1 Cajete Series, Valles Caldera, New Mexico. Journal of Geophysical Research, 93, 6113-6127.

Shea, T., Houghton, B. F., Gurioli, L., Cashman, K. V., Hammer, J. E., \& Hobden, B. J. (2010). Textural studies of vesicles in volcanic rocks: An integrated methodology. J. Volcanol. Geotherm. Res., 190, 270-289. 10.1016/j.jvolgeores.2010.02.013

Sparks, R. S. J. (1978). The dynamics of bubble formation and growth in magmas. J. Volcanol. Geotherm. Res., 3 , 1-37. 10.1016/0377-0273(78)90002-1

Spieler, O., Kennedy, B., Kueppers, U., Dingwell, D. B., Scheu, B., \& Taddeucci, J. (2004). The fragmentation threshold of pyroclastic rocks. Earth Planet. Sci. Lett., 226, 139-148. 10.1016/j.epsl.2004.07.016

Stasiuk, M. V., Barclay, J., Carroll, M. R., Jaupart, C., Ratté, J. C., Sparks, R. S. J., \& Tait, S. R. (1996). Degassing during magma ascent in the mule creek vent (usa). Bulletin of Volcanology, 58 (2-3), 117-130. 10.1007/s004450050130

Takeuchi, S., Tomiya, A., \& Shinohara, H. (2009). Degassing conditions for permeable silicic magmas: Implications from decompression experiments with constant rates.

(C)2019 American Geophysical Union. All Rights Reserved. 
Earth Planet. Sci. Lett., 283, 101-110. 10.1016/j.epsl.2009.04.001

Toramaru, A. (1988). Formation of propagation pattern in two-phase flow systems with applications to volcanic eruptions. Geophys. J., 95, 613-623.

Toramaru, A. (1990). Measurement of bubble size distribution in vesiculated rocks with implications for quantitative estimation of eruption processes. J. Volcanol. Geotherm. Res., 43, 71-90. 10.1016/0377-0273(90)90045-H

Toramaru, A. (1995). A numerical study of nucleation and growth of bubbles in viscous magmas. J. Geophys. Res., 100, 1913-1931.

Vogel, H.-J. (2002). Topological characterization of porous media. In Morphology of condensed matter: Physics and geometry of spatially complex systems (pp. 75-92). Berlin, Heidelberg : Springer Berlin Heidelberg. 10.1007/3-540-45782-8 3

Walsh, S. D., \& Saar, M. O. (2008). Magma yield stress and permeability: Insights from multiphase percolation theory. Journal of Volcanology and Geothermal Research, $\underline{177}(4), 1011-1019$.

Westrich, H. R., \& Eichelberger, J. C. (1994). Gas transport and bubble collapse in rhyolitic magma: an experimental approach. Bull. Volcanol., 56, 447-458.

Woods, A., \& Koyaguchi, T. (1994). Transitions between explosive and effusive eruptions of silicic magmas. Nature, 370, 641-644. 10.1038/370641a0

Wright, H., Cashman, K., Gottesfeld, E., \& Roberts, J. (2009). Pore structure of volcanic clasts: Measurements of permeability and electrical conductivity. Earth Planet. Sci. Lett., 280, 93-104.

Wright, H., Roberts, J., \& Cashman, K. (2006). Permeability of anisotropic tube pumice: Model calculations and measurements. Geophys. Res. Lett., $\underline{33}$, (C)2019 American Geophysical Union. All Rights Reserved. 
10.1029/2006GL027224.

Zhang, Y. (1999). A criterion for the fragmentation of bubbly magma based on brittle failure theory. Nature, 402, 648-650. 10.1038/45210

Zhang, Y., Jenkins, J., \& Xu, Z. (1997). Kinetics of the reaction $\mathrm{H}_{2} \mathrm{O} \leftrightarrow 2 \mathrm{OH}$ in rhyolitic glasses upon cooling: Geospeedometry and comparison with glass transition. Geochimica et Cosmochimica Acta, 61(11), 2167-2173. 10.1016/S00167037(97)00054-9

Zhang, Y., Xu, Z., Zhu, M., \& Wang, H. (2007). Silicate melt properties and volcanic eruptions. Rev. Geophys., 45, RG4004. 10.1029/2006RG000216
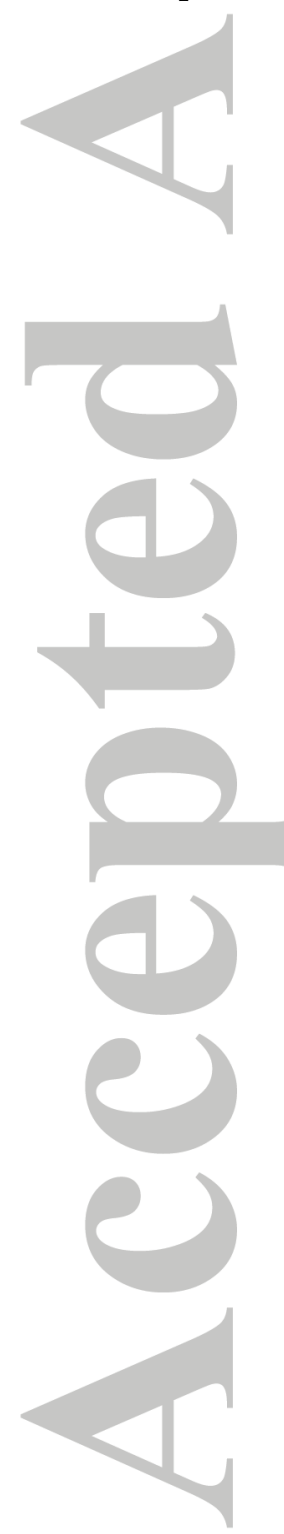

(C)2019 American Geophysical Union. All Rights Reserved. 
Table 1. Conditions of the hydration experiments. The rhyolitic melts have been maintained during a time $\tau_{\mathrm{h}}(\mathrm{h})$ at a constant pressure, $P_{\text {sat }}(\mathrm{MPa})$, and constant temperature, $T=850{ }^{\circ} \mathrm{C}$. After 6-9 days, melts are saturated with water, and homogeneous water content measured by FTIR in quenched glasses, $C_{\mathrm{i}}(\mathrm{wt} \%)$, ranges from 5.48 to $6.35 \mathrm{wt} \%$.

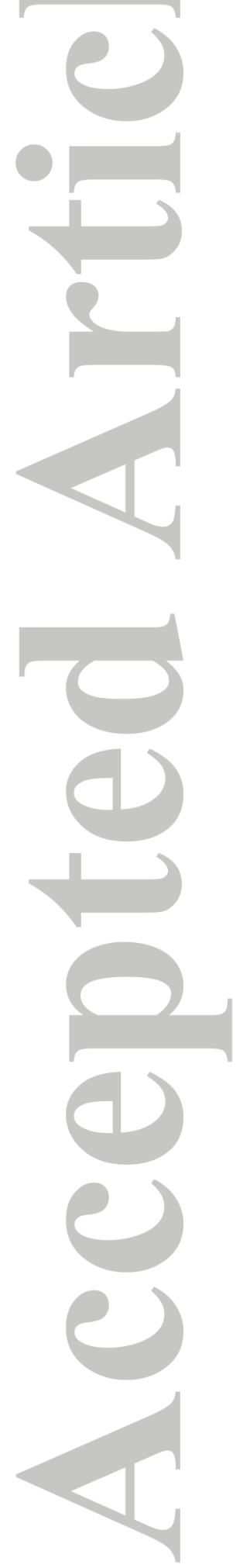

\begin{tabular}{llll}
\hline Sample & $P_{\text {sat }}$ & $\tau_{\mathrm{h}}$ & $C_{\mathrm{i}}$ \\
\hline G-1570 & 190 & 168 & $5.70 \pm 0.01$ \\
G-1448 & 200 & 167 & $5.70 \pm 0.01$ \\
G-1456 & 200 & 145 & $5.70 \pm 0.01$ \\
G-1457 & 200 & 144 & $5.71 \pm 0.02$ \\
G-1483 & 200 & 216 & $5.50 \pm 0.08$ \\
G-1608 & 200 & 123 & $5.48 \pm 0.04$ \\
G-1544 & 220 & 150 & $5.68 \pm 0.01$ \\
G-1545 & 220 & 150 & $5.59 \pm 0.04$ \\
G-1446 & 250 & 197 & $6.28 \pm 0.01$ \\
G-1451 & 250 & 187 & $6.35 \pm 0.05$ \\
G-1455 & 250 & 143 & $6.25 \pm 0.03$ \\
G-1477 & 250 & 185 & $6.23 \pm 0.01$
\end{tabular}

(C)2019 American Geophysical Union. All Rights Reserved. 
Table 2. Conditions of the decompression experiments and results of image analysis. $P_{\mathrm{i}}$ $(\mathrm{MPa})$ and $P_{\mathrm{f}}(\mathrm{MPa})$ are respectively the initial and final pressures. $\tau_{\text {dec }}(\mathrm{s})$ is the time taken to lower pressure to $P_{\mathrm{f}}$, and $\dot{P}\left(\mathrm{MPa} \mathrm{s}^{-1}\right)$ is the resultant average decompression rate. $\tau_{\mathrm{p}}(\mathrm{s})$ is the time the sample was held at $P_{\mathrm{f}}$ after the decompression. $\phi_{\mathrm{tot}_{\mathrm{EQ}}}(\%)$ is the total porosity expected at quenching conditions, assuming equilibrium and calculated using standard formulations for $\mathrm{H}_{2} \mathrm{O}$ solubility (Liu et al., 2005), melt density (Lange, 1994), and equation of state of (Kerrick \& Jacobs, 1981). $\phi_{\text {tot }}(\%)$ and $\phi_{\text {coa }}(\%)$ are the measured total and coalesced porosities, respectively. $\varepsilon(0$ to 1$)$ is the value obtained using the percolation model for which modeled $\phi_{\text {coa }}$ equals measured $\phi_{\text {coa }}$, and $\phi_{\mathrm{cr}}(\%)$ is the predicted percolation threshold using Equation 2. $N\left(\log \mathrm{m}^{-3}\right)$ is the glass-referenced bubble number density and $R(\mu \mathrm{m})$ is the average bubble radius. The mode of the distribution of coordination numbers, $f\left(n_{\mathrm{c}}\right)_{\mathrm{m}}$, was calculated by fitting a Gaussian curve using MATLAB, and $\omega=f(5) / f(6)$. Because of the $1 \%$ error associated with the measurement of $\phi_{\text {tot }}$ and $\phi_{\text {coa }}$ (Section 2.2.2), $\phi_{\text {cr }}$ was not calculated for samples with $\phi_{\text {coa }}<1 \%$, and 'N.D.' stands for 'Not Determined'. Similarly when the total number of bubbles analyzed on the SEM images is $<100$, the mode of $f\left(n_{\mathrm{c}}\right)$ and $\omega$ were not calculated.

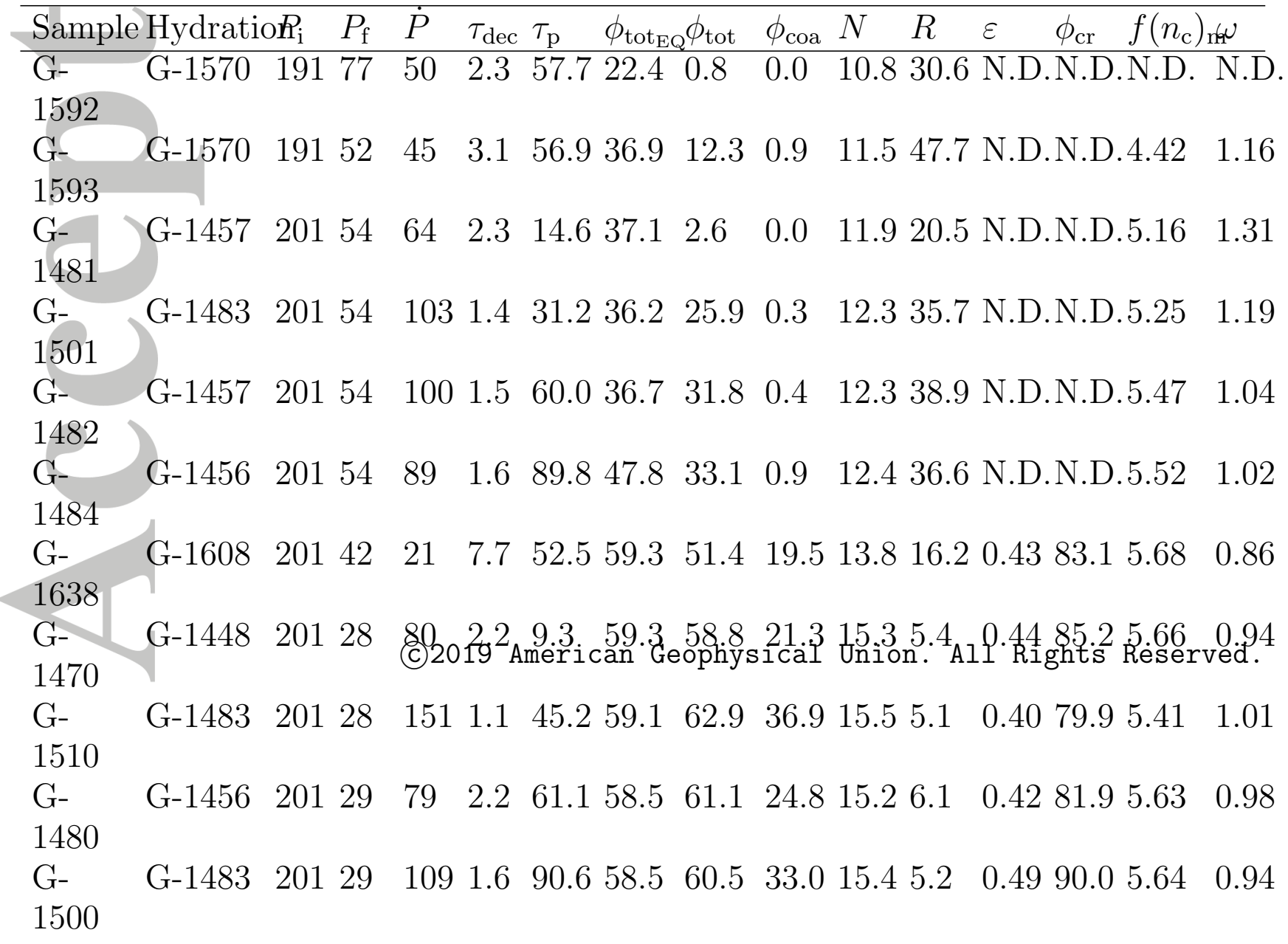


Table 3. Conditions of the decompression experiments and results of image analysis for samples from (Burgisser \& Gardner, 2004) (PPE, G, and ABG samples) and (Lindoo et al., 2016) (MC samples). $N\left(\log \mathrm{m}^{-3}\right)$ and $R(\mu \mathrm{m})$ are both values taken from the original studies.

Samples from (Burgisser \& Gardner, 2004) were first decompressed instantaneously from 155 MPa to $100 \mathrm{MPa}$, held at $100 \mathrm{MPa}$ for 15 minutes, and then decompressed to $P_{\mathrm{f}}$ at $\dot{P}$. Units are the same as in Table 2.

\begin{tabular}{|c|c|c|c|c|c|c|c|c|c|c|c|c|}
\hline Sample & $P_{\mathrm{i}}$ & $P_{\mathrm{f}}$ & $\dot{P}$ & $\phi_{\text {tot }}$ & $\phi_{\text {coa }}$ & $\tau_{\text {exp }}$ & $N$ & $R$ & $\varepsilon$ & $\phi_{\mathrm{cr}}$ & \multicolumn{2}{|c|}{$f\left(n_{\mathrm{c}}\right)_{\mathrm{m}} \omega$} \\
\hline PPE6 & 100 & 60 & 0.025 & 41.0 & 27.3 & 1600 & 11.3 & 88 & 0.21 & 53.8 & 5.09 & 1.83 \\
\hline PPE2 & 100 & 44 & 0.025 & 52.7 & 39.4 & 2240 & 11.1 & 109 & 0.29 & 64.1 & 5.46 & 1.11 \\
\hline PPE4 & 100 & 40 & 0.025 & 49.3 & 30.9 & 2400 & 12.0 & 56 & 0.29 & 64.4 & 5.56 & 1.14 \\
\hline PPE5 & 100 & 36 & 0.025 & 49.2 & 26.1 & 2560 & 11.1 & 113 & 0.34 & 71.0 & N.D. & N.D. \\
\hline PPE7 & 100 & 34 & 0.025 & 67.3 & 59.7 & 2640 & 12.0 & 72 & 0.30 & 66.4 & 5.41 & 1.07 \\
\hline PPE1 & 100 & 30 & 0.025 & 29.6 & 5.7 & 2800 & 10.8 & 62 & 0.38 & 75.9 & N.D. & N.D. \\
\hline PPE10 & 100 & 28 & 0.025 & 53.8 & 41.0 & 2880 & 11.0 & 151 & 0.30 & 66.2 & N.D. & N.D. \\
\hline PPE11 & 100 & 24 & 0.025 & 81.4 & 80.1 & 3040 & 11.1 & 193 & 0.26 & 59.9 & N.D. & N.D. \\
\hline G318 & 100 & 36 & 0.1 & 34.7 & 12.1 & 640 & 12.0 & 53 & 0.38 & 76.4 & 4.98 & 1.50 \\
\hline G322 & 100 & 30 & 0.1 & 42.1 & 23.5 & 700 & 11.2 & 45 & 0.32 & 68.4 & 3.62 & 1.00 \\
\hline G321 & 100 & 24 & 0.1 & 45.6 & 21.4 & 760 & 12.4 & 41 & 0.40 & 79.3 & 5.29 & 1.18 \\
\hline G323 & 100 & 18 & 0.1 & 41.7 & 18.6 & 820 & 11.8 & 57 & 0.38 & 76.3 & 4.34 & 1.50 \\
\hline G300 & 100 & 30 & 0.5 & 28.3 & 5.7 & 140 & 12.2 & 39 & 0.34 & 70.7 & 5.26 & 1.18 \\
\hline G303 & 100 & 25 & 0.5 & 49.0 & 35.6 & 150 & 12.2 & 31 & 0.33 & 70.4 & 4.80 & 1.38 \\
\hline G328 & 100 & 20 & 0.5 & 62.9 & 54.8 & 160 & 12.0 & 33 & 0.28 & 62.8 & 4.41 & 1.64 \\
\hline G327 & 100 & 15 & 0.5 & 53.1 & 30.9 & 170 & 12.2 & 36 & 0.38 & 76.5 & 5.33 & 1.37 \\
\hline ABG20 & 100 & 90 & 0.5 & 7.4 & 0.2 & 20 & 12.4 & 17 & N.D. & N.D. & N.D. & N.D. \\
\hline ABG14 & 100 & 80 & 0.5 & 7.6 & 1.2 & 40 & 12.4 & 19 & 0.22 & 54.9 & 5.19 & 1.55 \\
\hline ABG25 & 100 & 70 & 0.5 & 12.3 & 0.6 & 60 & 12.0 & 31 & N.D. & N.D. & N.D. & N.D. \\
\hline ABG15 & 100 & 60 & 0.5 & 18.1 & 3.9 & 80 & 12.2 & 32 & 0.29 & 63.9 & 5.30 & 1.20 \\
\hline ABG16 & 100 & 50 & 0.5 & 18.8 & 4.6 & 100 & 12.2 & 36 & 0.24 & 56.9 & 5.05 & 1.29 \\
\hline ABG30 & 100 & 30 & 0.5 & 45.1 & 28.3 & 140 & 12.8 & 30 & 0.30 & 66.1 & 5.30 & 1.11 \\
\hline MC24 & 150 & 100 & 0.25 & 21.3 & 0.6 & 200 & N.D & N.D. & N.D. & N.D. & N.D. & N.D. \\
\hline MC21 & 150 & 15 & 0.25 & 42.0 & 26.4 & 540 & 13.0 & 35 & 0.28 & 63.1 & N.D. & N.D. \\
\hline MC20 & 150 & 37 & 0.25 & 58.1 & 46.8 & 450 & 13.1 & 33 & 0.29 & 64.9 & N.D. & N.D. \\
\hline $\mathrm{MC} 27$ & 150 & 15 & 0.25 & 77.7 & 73.9 & 540 & 13.5 & 34 & 0.29 & 65.2 & N.D. & N.D. \\
\hline MC31 & 150 & 15 & 0.25 & 81.9 & 77.3 & 540 & 15.1 & 8 & 0.33 & 70.6 & N.D. & N.D. \\
\hline
\end{tabular}



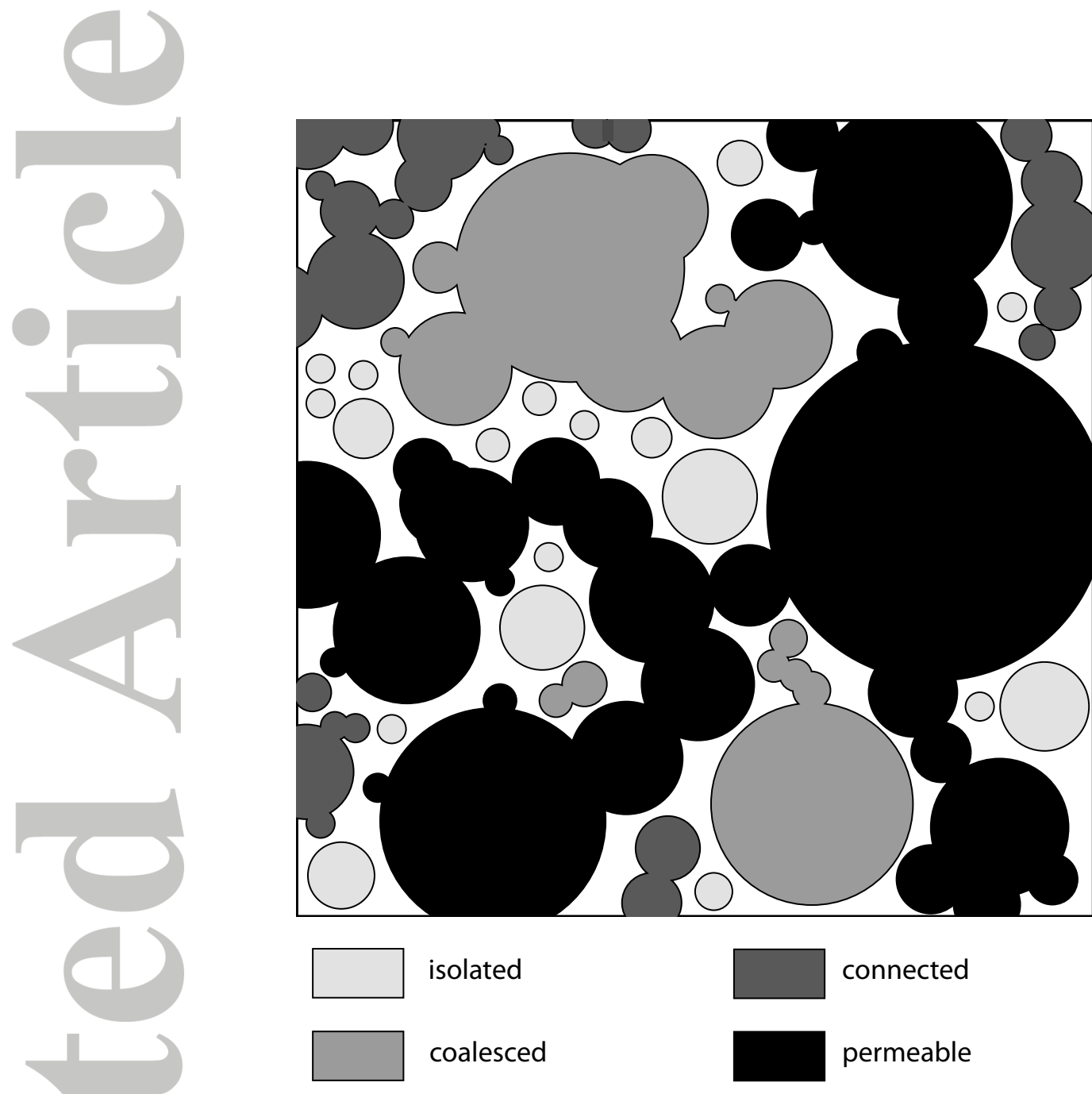

isolated

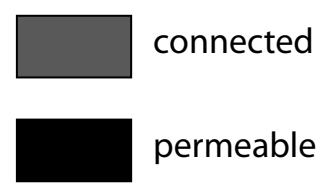

Figure 1. Illustration, in two dimensions, of the different types of bubbles (and porosities) defined in this study. Permeable clusters of bubbles (i.e., clusters of bubbles crossing the sample from side to side) are necessarily also connected (i.e., cluster of bubbles cut by at least one side of the sample), and are formed of coalesced bubbles (i.e., bubbles that overlap with at least another bubble).

(C)2019 American Geophysical Union. All Rights Reserved. 


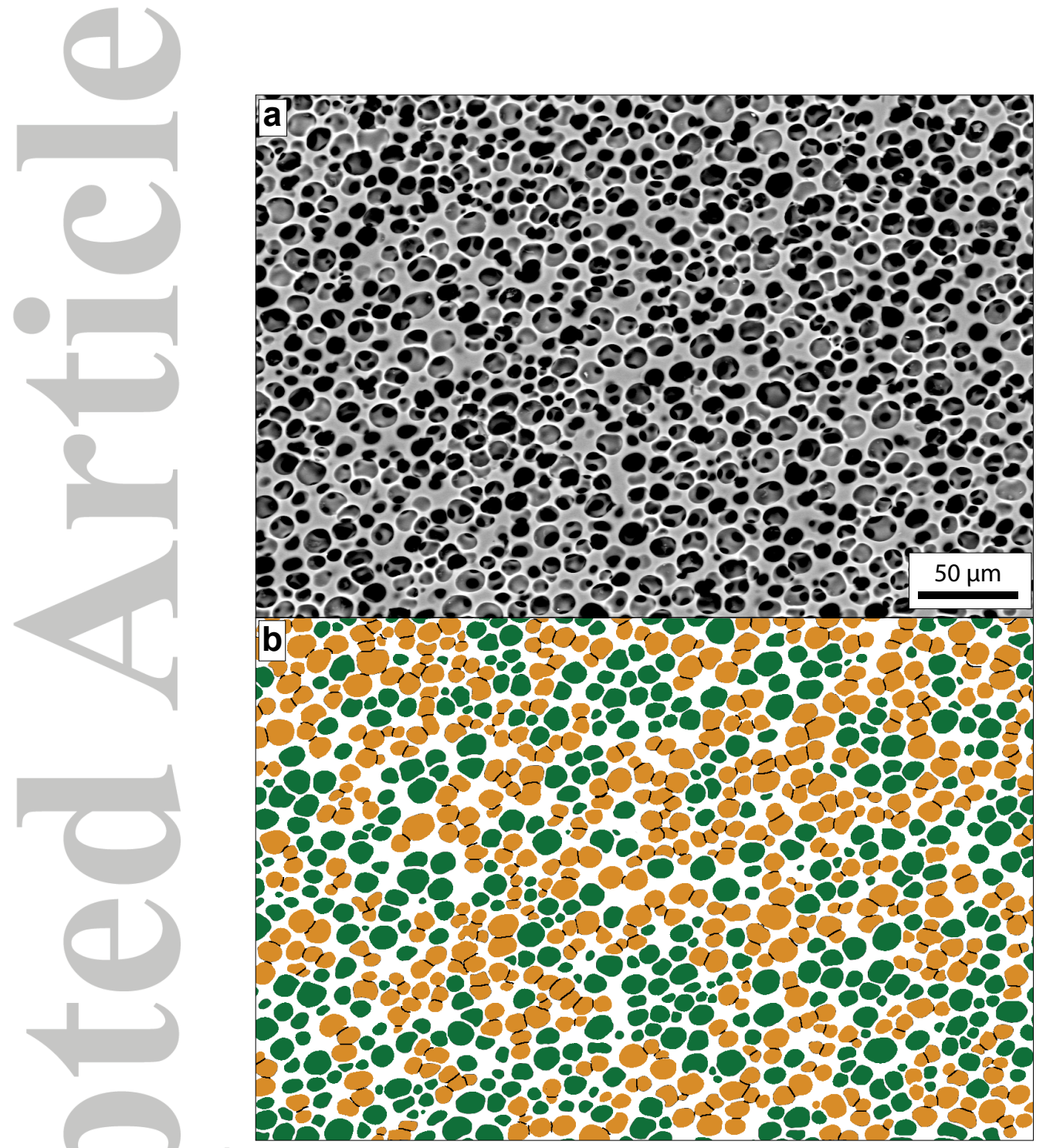

Figure 2. (a) Backscattered Scanning Electron Microscope image of sample G-1500. Vesicles appear in black or dark gray and the glass in lighter gray. Total porosity of the image is $60.5 \%$.

Same image after binarization. Isolated bubbles are shown in green (27.6\%), coalesced bubbles are shown in orange separated by black lines $\left(\phi_{\mathrm{coa}}=33.0 \%\right)$, and glass is shown in white.

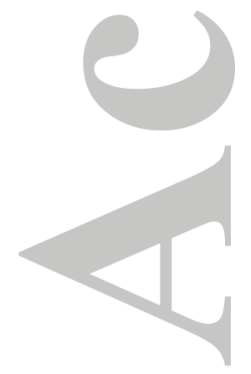

(C)2019 American Geophysical Union. All Rights Reserved. 

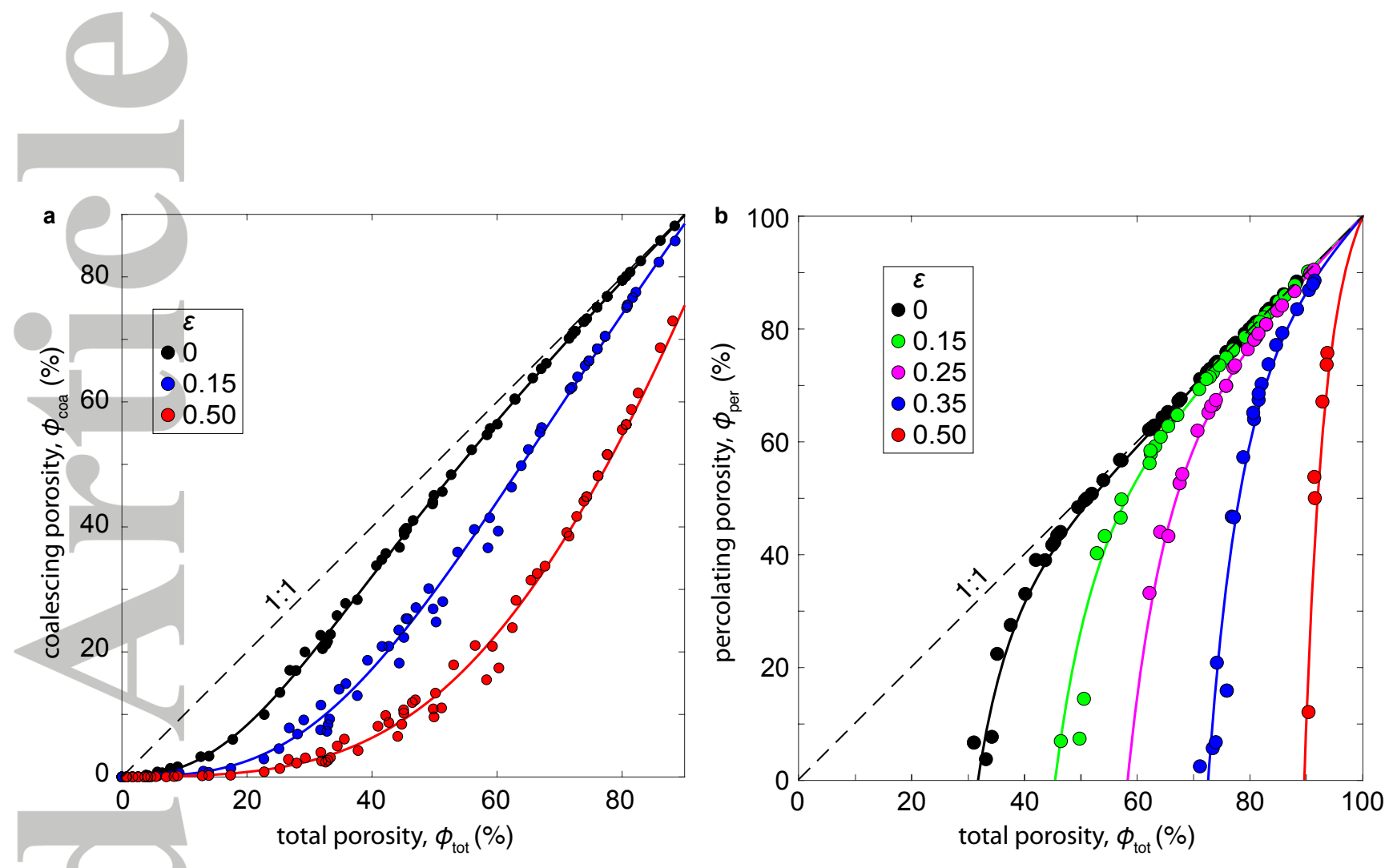

Figure 3. (a) Coalesced porosity, $\phi_{\text {coa }}$, and (b), percolating porosity, $\phi_{\text {per }}$, both as a function of total porosity, $\phi_{\text {tot }}$ obtained for individual percolation models and different values of $\varepsilon$. Also shown are the fits to the individual models obtained using Equations 1 and 2, respectively. On (b), the intersection of each curve with the abscissa marks the percolation threshold, $\phi_{\mathrm{cr}}$, which is about $32 \%$ when $\varepsilon=0$ (Sahimi, 1994 ; Saar \& Manga, 1999 ; Blower, 2001a), but rapidly increases with $\varepsilon$ to reach approximately $90 \%$ for $\varepsilon=0.5$. 

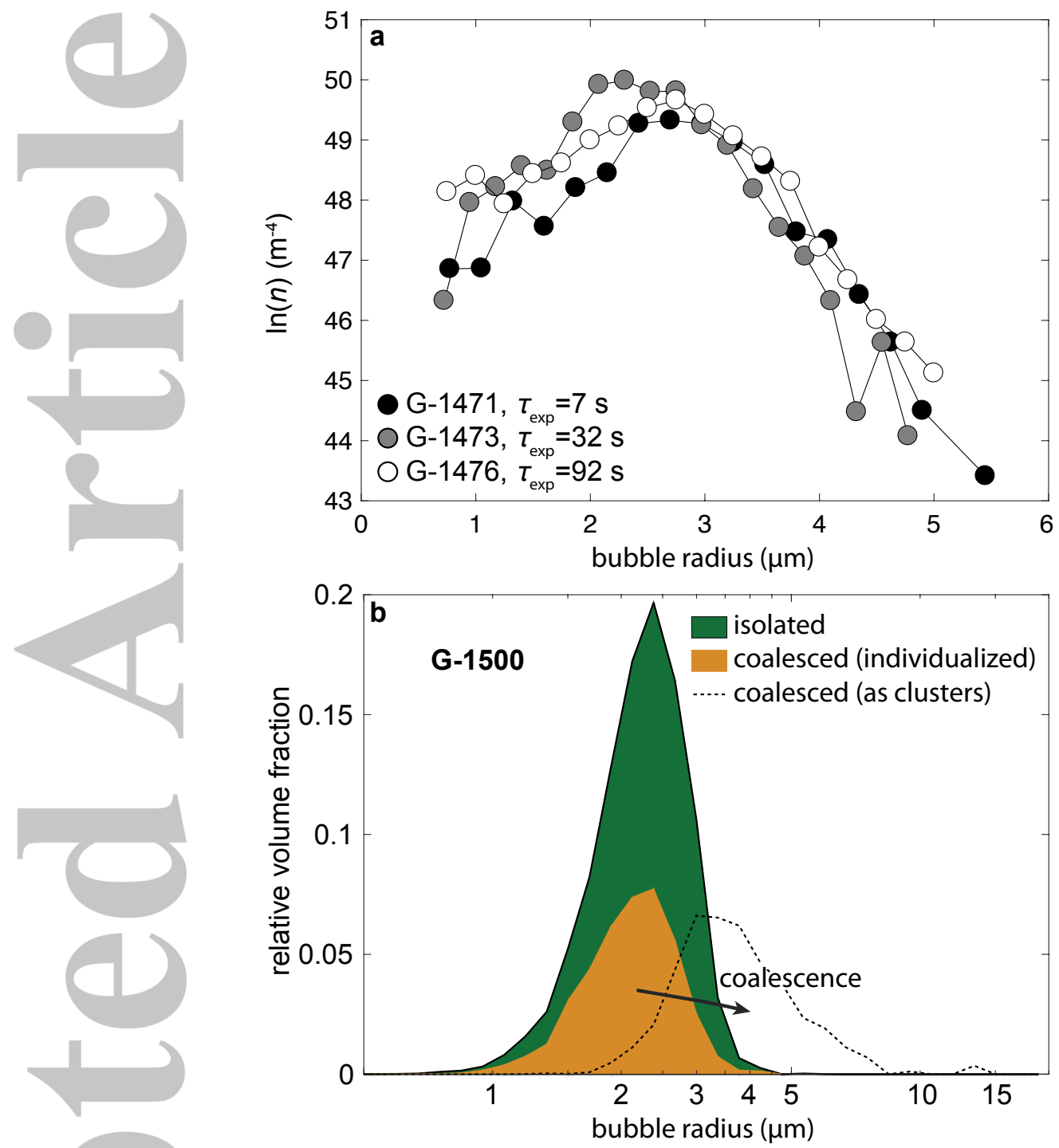

Figure 4. (a) Natural logarithm of the population density of samples G-1471, G-1473, and G-1476, as a function of bubble radius, assuming spherical shape. Samples exhibit similar profiles despite the fact that they were kept at $P_{\mathrm{f}}$ for different times $(6,30$, and $90 \mathrm{~s})$, indicating that the concave-down profile is not due to Ostwald ripening (Shea et al., 2010). (b) Volume fraction of bubbles (isolated and coalesced, either as clusters or individualized) of sample G-1500, as a function of bubble radius.

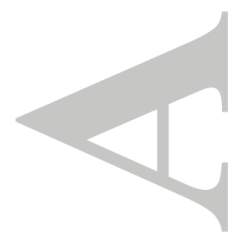

(C)2019 American Geophysical Union. All Rights Reserved. 

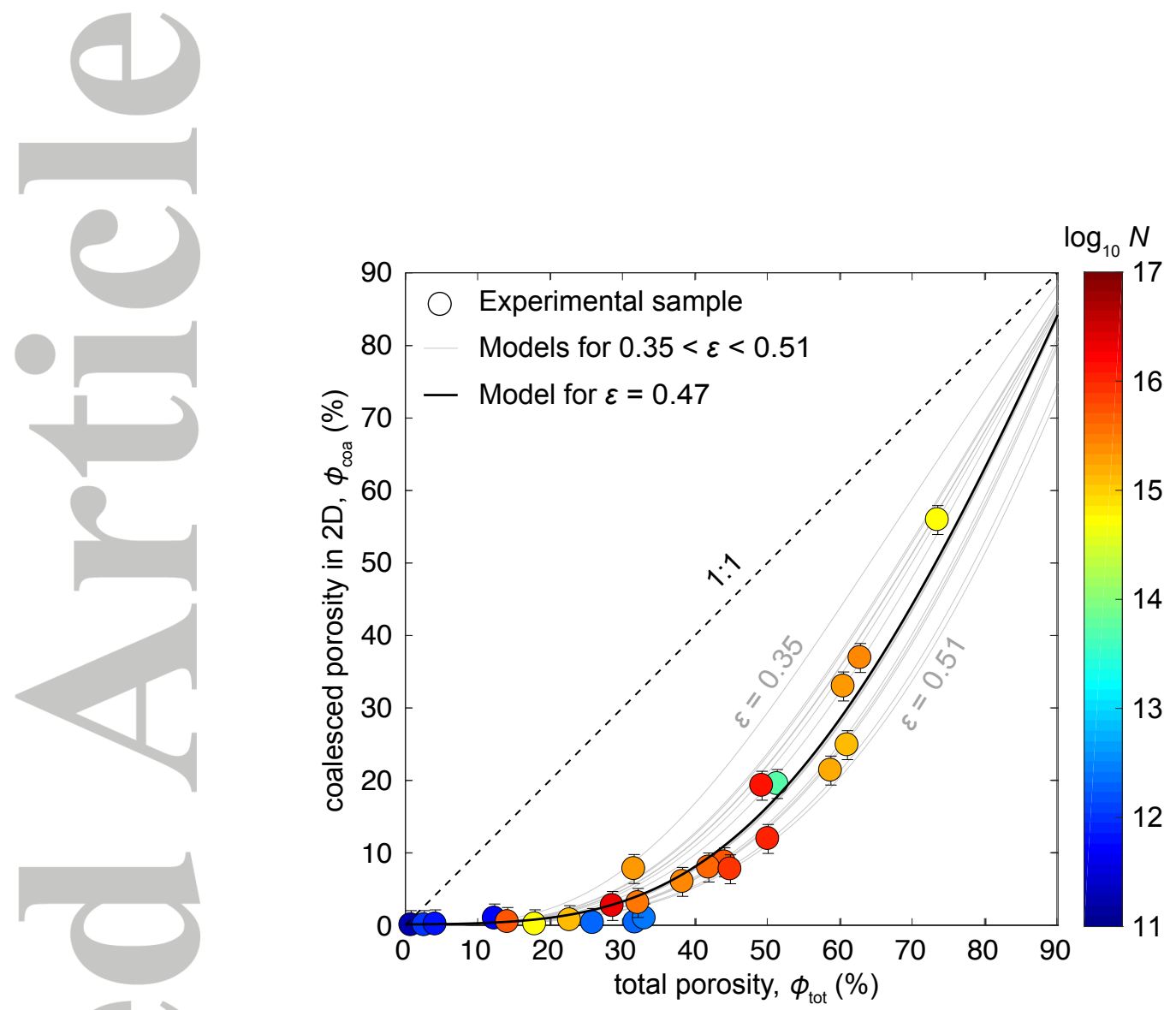

Figure 5. 2D coalescing porosity, $\phi_{\text {coa }}$, as a function of total porosity, $\phi_{\text {tot }}$, for all samples (Table 2). Colors are based on $\log _{10} N$. The dashed line represents $\phi_{\text {coa }}=\phi_{\text {tot }}$. The gray lines represent coalesced porosity predicted by the percolation model (Equations 1-2.2.3), using for each sample the $\varepsilon$ that allows equal values of the modeled and measured coalescing porosity. This leads to values of $0.35<\varepsilon<0.51$ for all the samples for which $\phi_{\text {coa }}>1 \%$. The black line shows the predicted coalesced porosity for $\varepsilon=0.47$, which is the average value of all samples. 


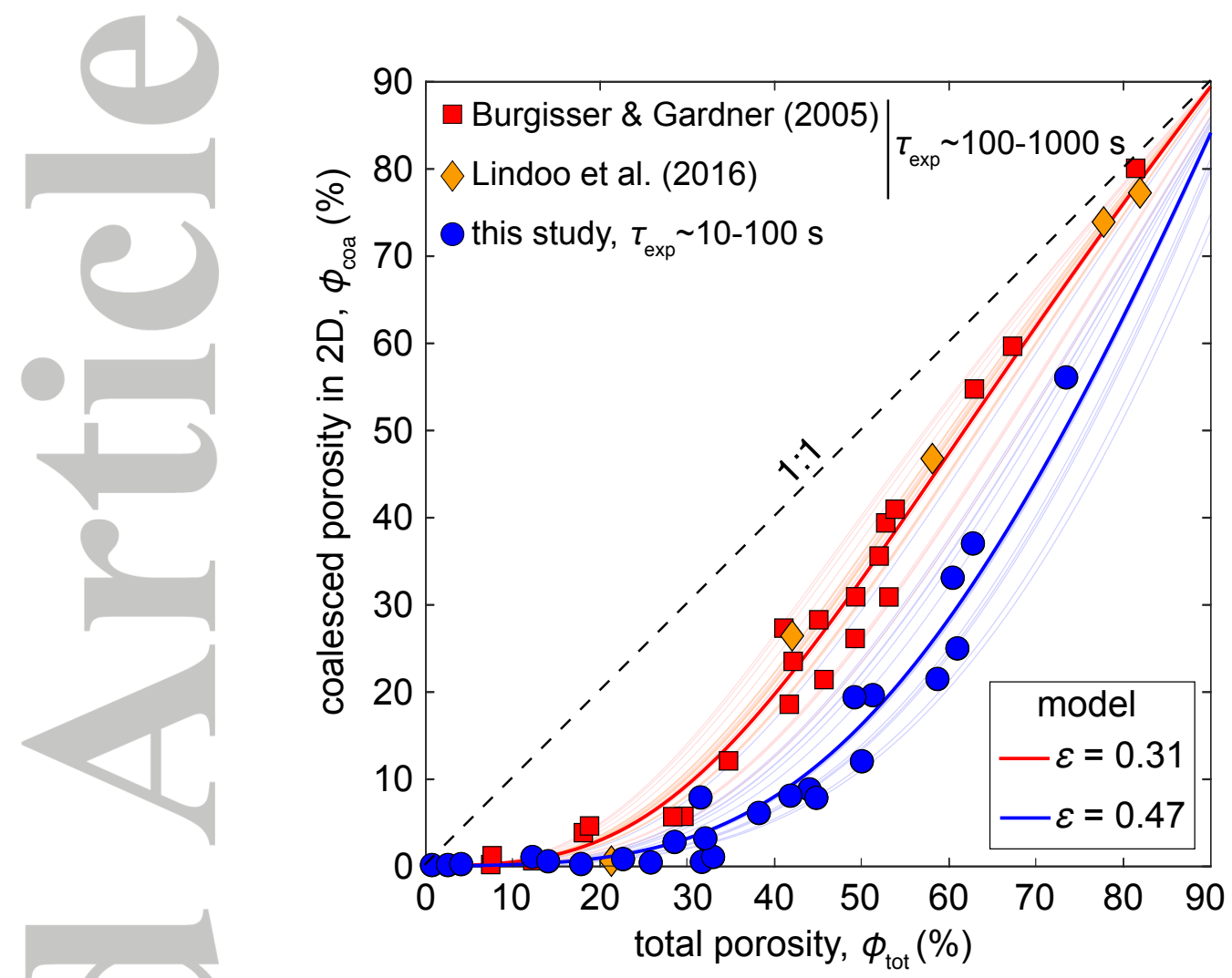

Figure 6. Coalesced porosity as a function of total porosity for slowly decompressed experiments (Burgisser \& Gardner, 2004 ; Lindoo et al., 2016) and rapidly decompressed samples (this study). Predicted values from percolation modeling for each sample of for which $\phi_{\text {coa }}>1 \%$ are shown in light red and orange lines for samples of (Burgisser \& Gardner, 2004) and (Lindoo et al., 2016) $(0.21<\varepsilon<0.40)$, respectively, and light blue lines for our samples $(0.35<\varepsilon<0.51)$. Also shown are predicted values from percolation modeling for $\varepsilon=0.47$ and $\varepsilon=0.31$. These are the fits of the percolation model for the average $\varepsilon$ values obtained for all our samples (blue line) and those of (Burgisser \& Gardner, 2004) and (Lindoo et al., 2016) together (red line) for which $\phi_{\text {coa }}>1 \%$.

(C)2019 American Geophysical Union. All Rights Reserved. 

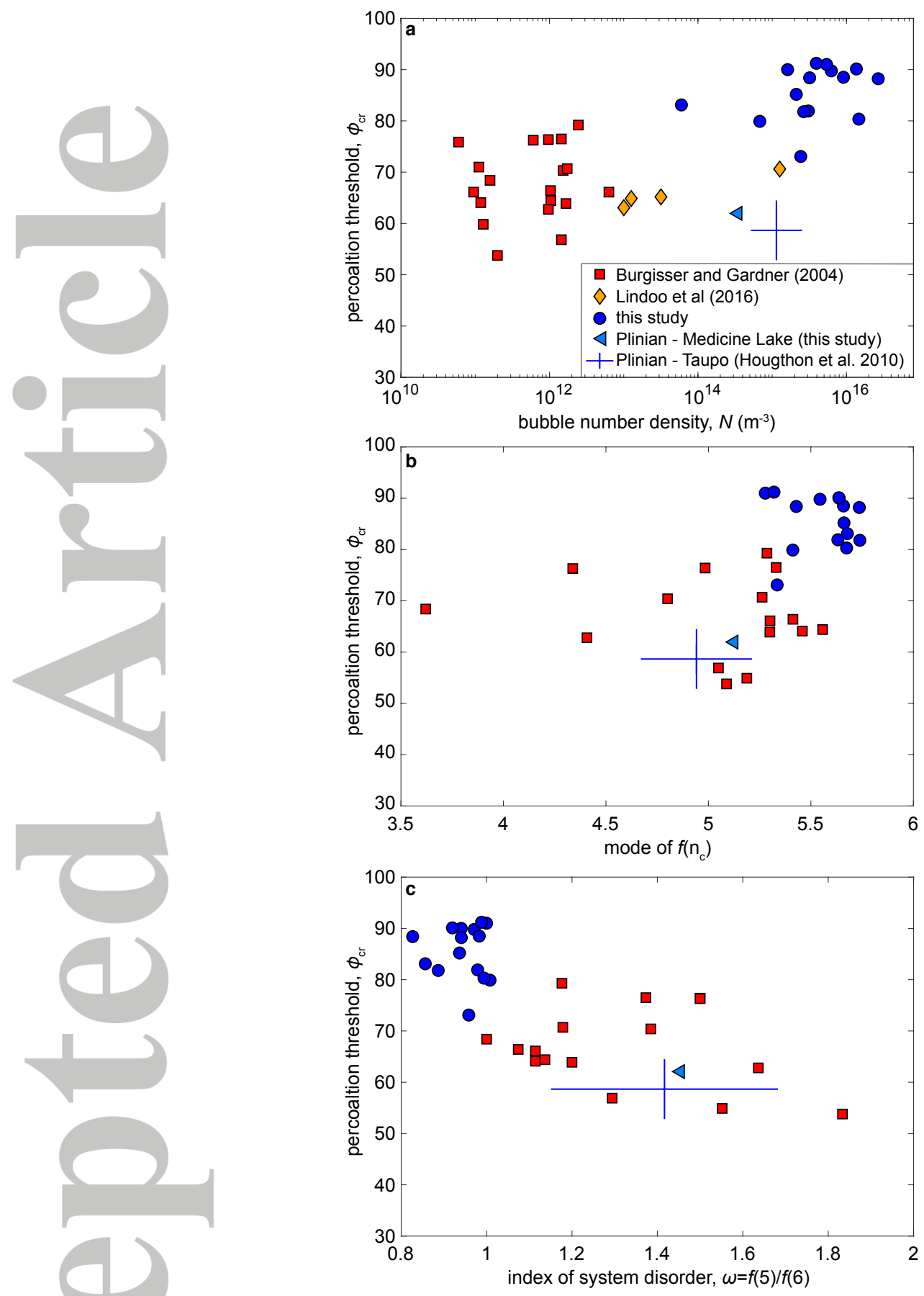

Figure 7. Percolation threshold predicted using the percolation modeling for all the experimental samples as the function of (a) the bubble number density, (b) the mode of the distribution of coordination numbers, and (c) the index of packing disorder, all corrected for coalescence. Also shown are the percolation thresholds and topological parameters obtained on Plinian samples from the $1060 \mathrm{CE}$ eruption of Medicine Lake Volcano, California (Gonnermann et al., 2017), and six pumices from the Unit 5 of Taupo (Houghton et al., 2010). For the Taupo samples, the symbol corresponds to the average and standard deviation obtained.

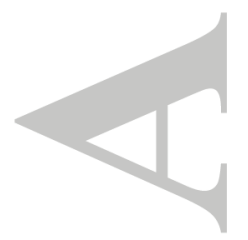

(C)2019 American Geophysical Union. All Rights Reserved. 

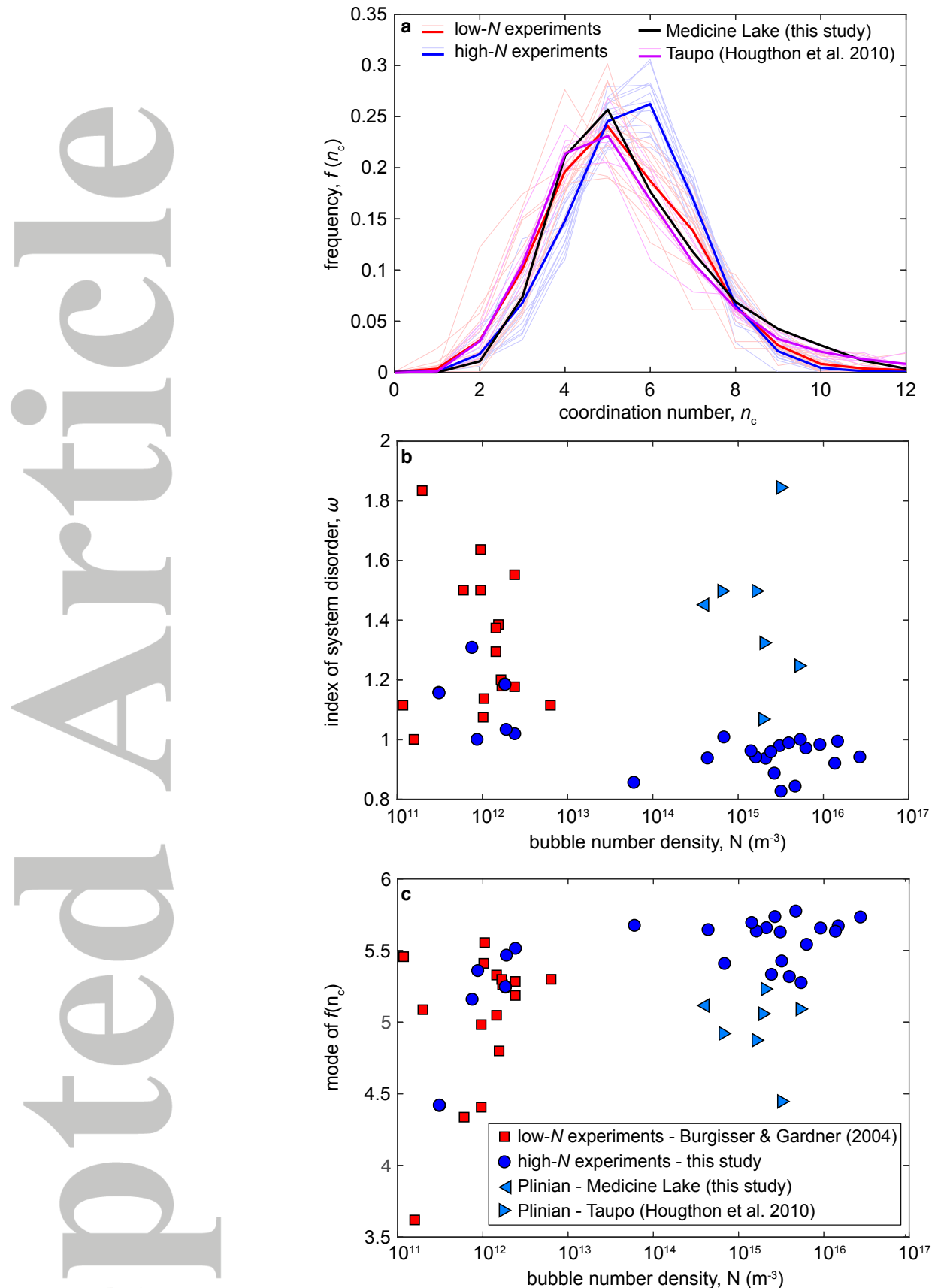

Figure 8. (a) Coordination number distribution of the bubbles before coalescence in individual samples (thin lines) and average (thick lines) for this study (blue) and that of (Burgisser \& Gardner, 2004) (red). Note that only samples for which at least 100 bubbles could be analyzed are plotted. Also plotted is the distribution for a typical Plinian pumice from the $1060 \mathrm{CE}$ eruption of Medicine Lake Volcano, California (Gonnermann et al., 2017), and six pumices from the Unit 5 of Taupo (Houghton et al., 2010). (b) Index of system disorder, $\omega$, and (c) mode of the distribution of coordination number $f\left(n_{\mathrm{c}}\right)$, both as a function of the bubble number density, $N$.

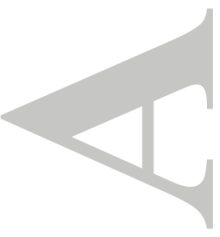

(C)2019 American Geophysical Union. All Rights Reserved. 

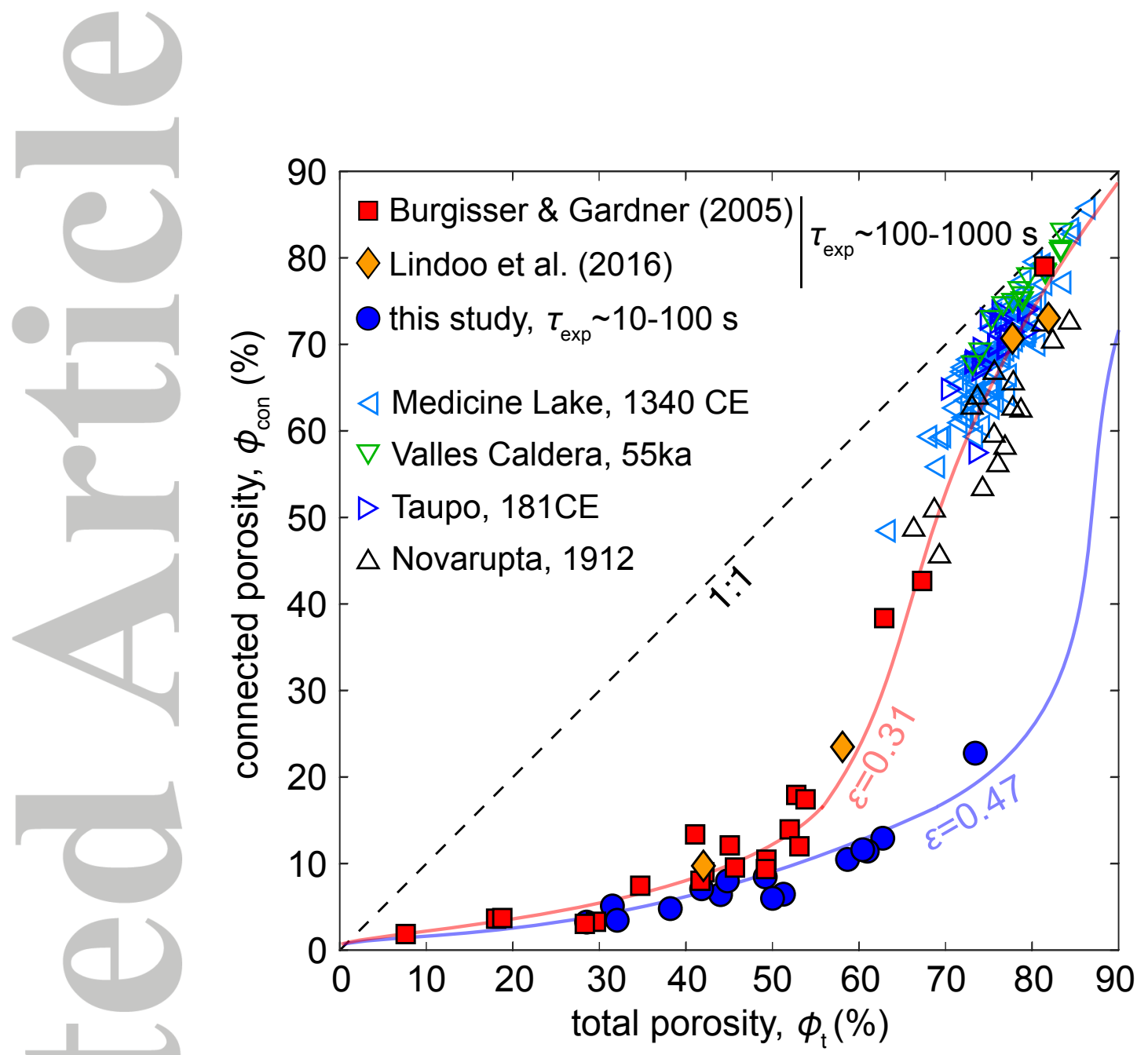

Figure 9. Connected porosity, $\phi_{\text {con }}$, measured by helium pycnometry as a function of total porosity, $\phi_{\text {tot }}$, of crystal-poor rhyolitic Plinian fallout from Medicine Lake, Valles Caldera, Taupo, and Novarupta (Gonnermann et al., 2017). Also shown is the connected porosity predicted by percolation modeling for all the experimental samples, as well as modeled trends for $\varepsilon=0.31$ and $\varepsilon=0.47$.

(C)2019 American Geophysical Union. All Rights Reserved. 


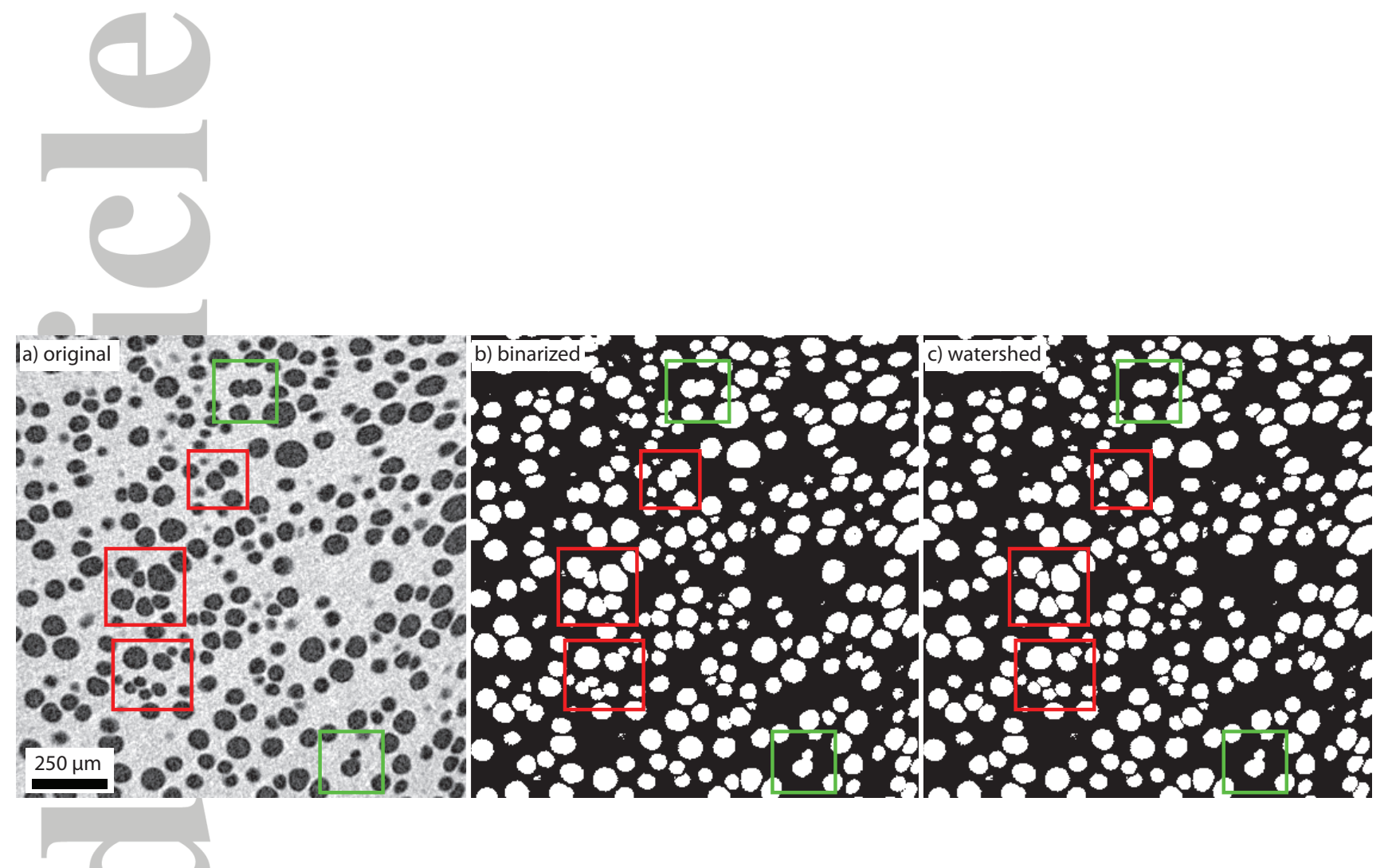

Figure A1. a) Original, b) binarized, and c) filtered (Distance Transform Watershed 3D filter) versions of the same image taken. Red rectangles highlight pairs of isolated bubbles that were artificially coalesced during the binarization process but were then successfully 'de-coalesced' using the distance transform watershed filter. The green rectangles highlight pairs of coalesced bubbles that stayed coalesced throughout the process.

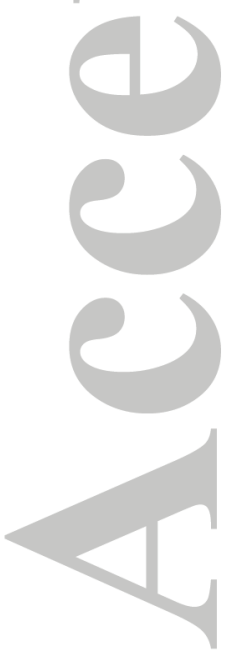

(C)2019 American Geophysical Union. All Rights Reserved. 

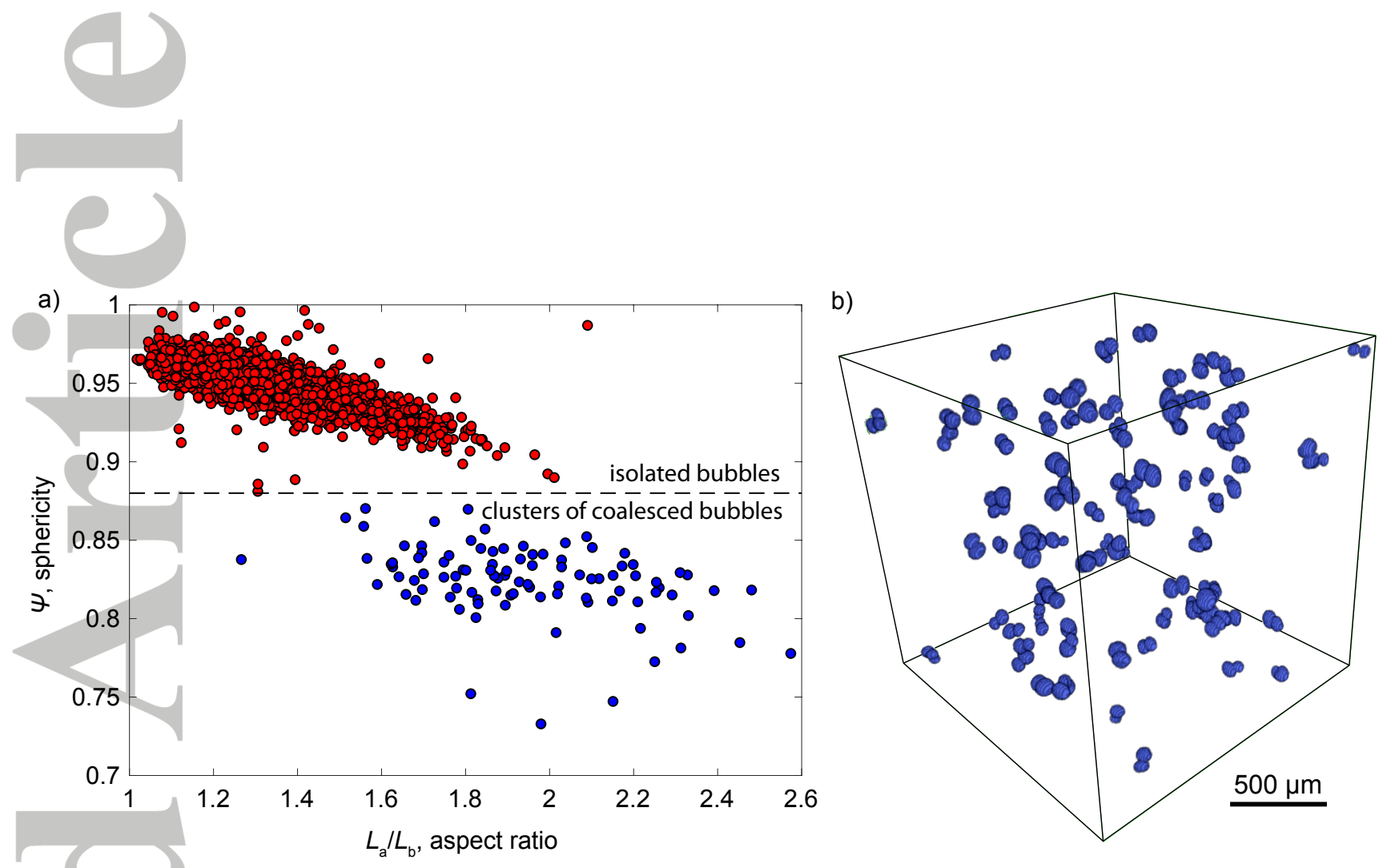

Figure A2. a) sphericity of bubbles (or clusters of bubbles), defined as $\Psi=\left[\pi^{1 / 3}(6 \mathrm{~V})^{2 / 3}\right] / A$, where $V$ and $A$ are respectively the volume and surface area, as a function of their aspect ratio $L_{a} / L_{b}$, where $L_{a}$ and $L_{b}$ are the longest and shortest axes of the inertia ellipsoid, respectively. Bubbles with a sphericity $>0.88$ are in red and the others in blue. b) 3D rendering of all the objects with a sphericity $<0.88$, which are the clusters of coalesced bubbles. 


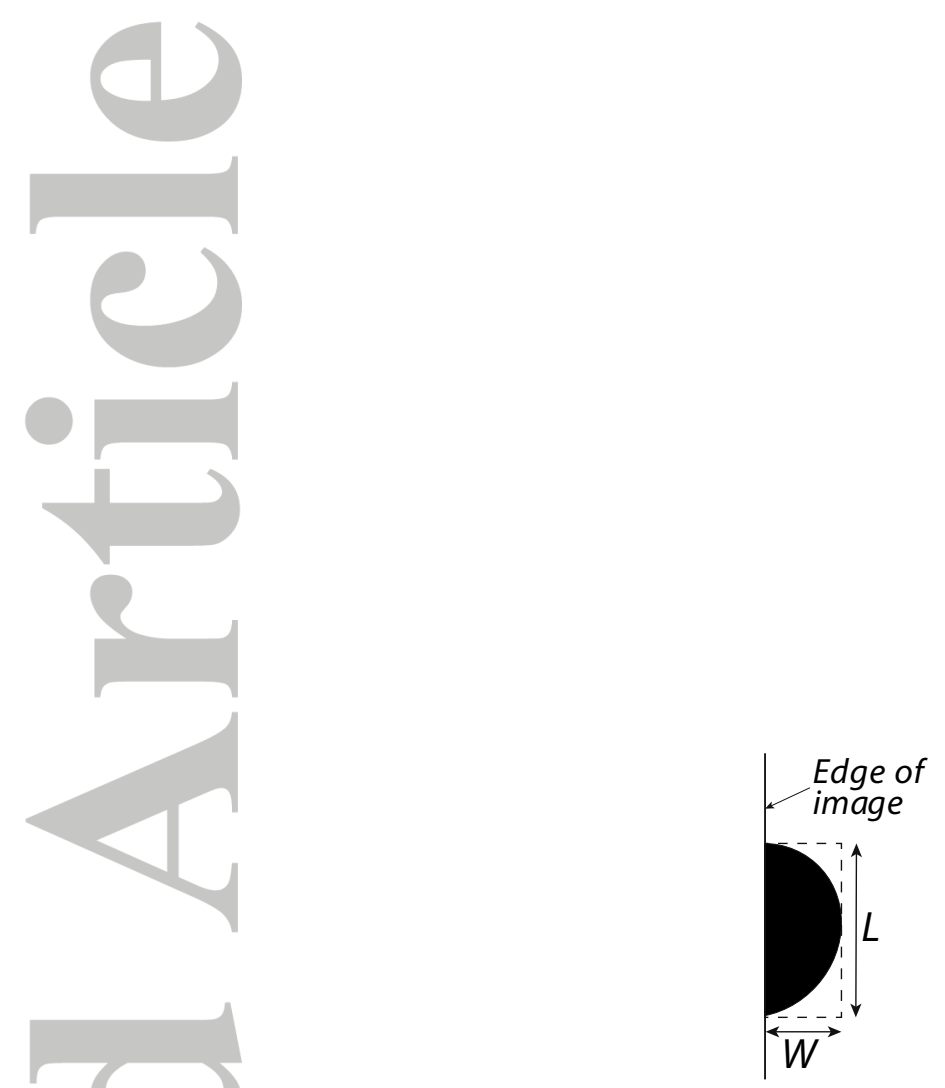

Figure B1. Treatment of a bubble, in black, cut by the edge of the image. $L$ and $W$ are respectively the length and width of the rectangle bounding the cut bubble.

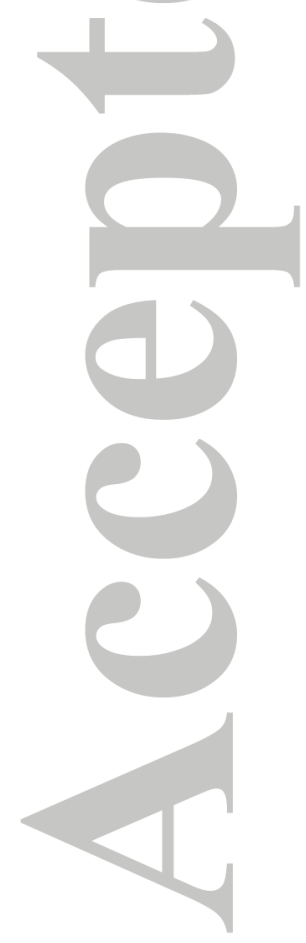

(C)2019 American Geophysical Union. All Rights Reserved. 

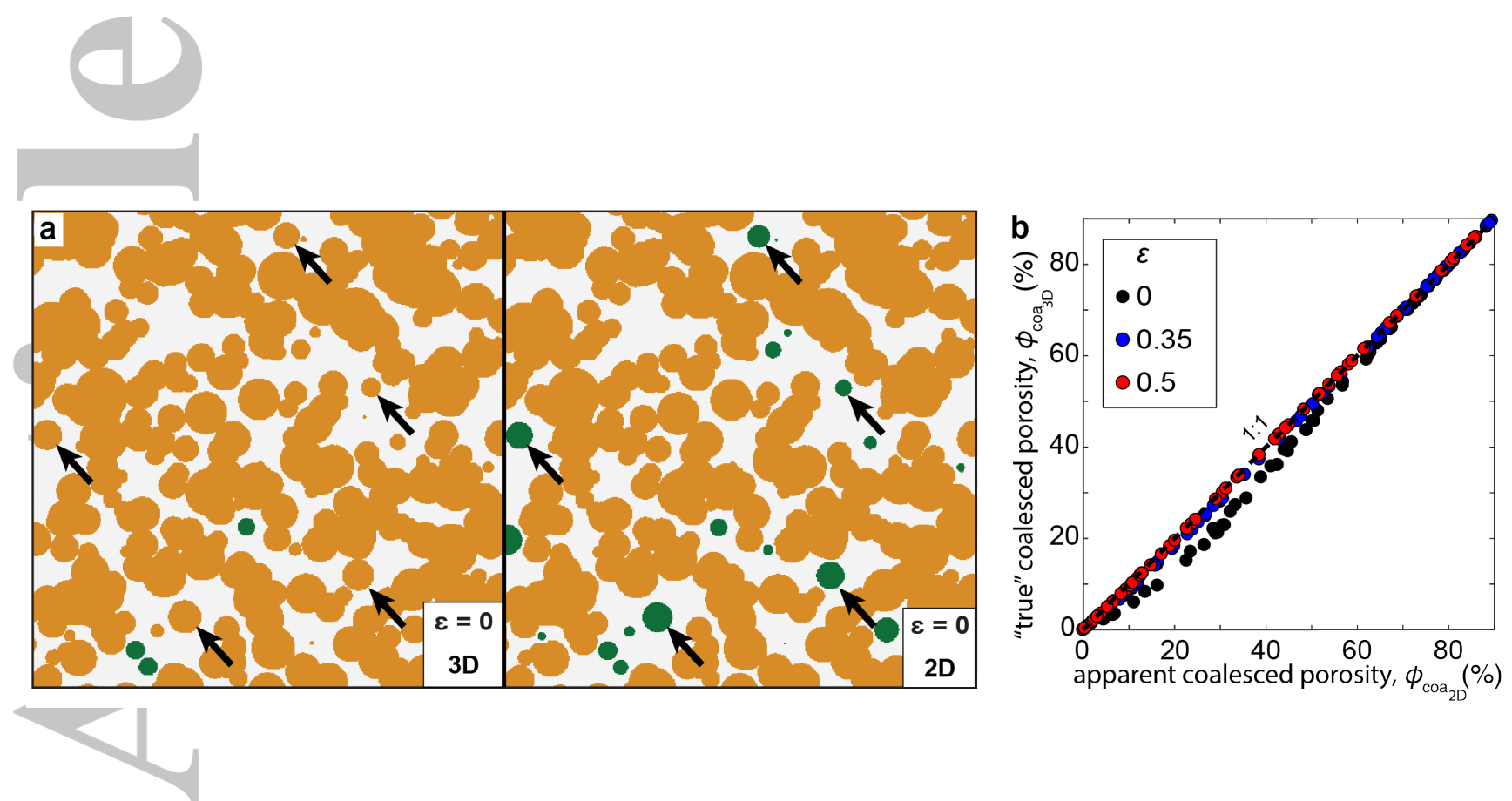

Figure C1. Apparent versus "true" coalesced porosity. a Portion of a single plane randomly taken inside the virtual cubic domain used for the percolation modeling of sample G-1500 with $\varepsilon=0$. Coalesced bubbles are shown in orange and isolated ones in green. On the left (3D) is shown the true state of bubbles (isolated or coalesced) whereas on the right is shown the apparent one, as it would be observed in an SEM image, for example. The black arrows highlight five bubbles that are coalesced but appear isolated in 2D. b "True" coalesced porosity, $\phi_{\mathrm{Coa}_{3 \mathrm{D}}}$, as a function of the apparent one, $\phi_{\mathrm{coa}_{2 \mathrm{D}}}$. Although $\phi_{\mathrm{Coa}_{2 \mathrm{D}}}$ can be up to two times lower than $\phi_{\mathrm{coa}_{3 \mathrm{D}}}$ at low $\phi_{\text {tot }}$, this discrepancy decreases with increasing total porosity and $\varepsilon$, and it is always $<10 \%$ for $\phi_{\text {tot }}>50 \%$. 


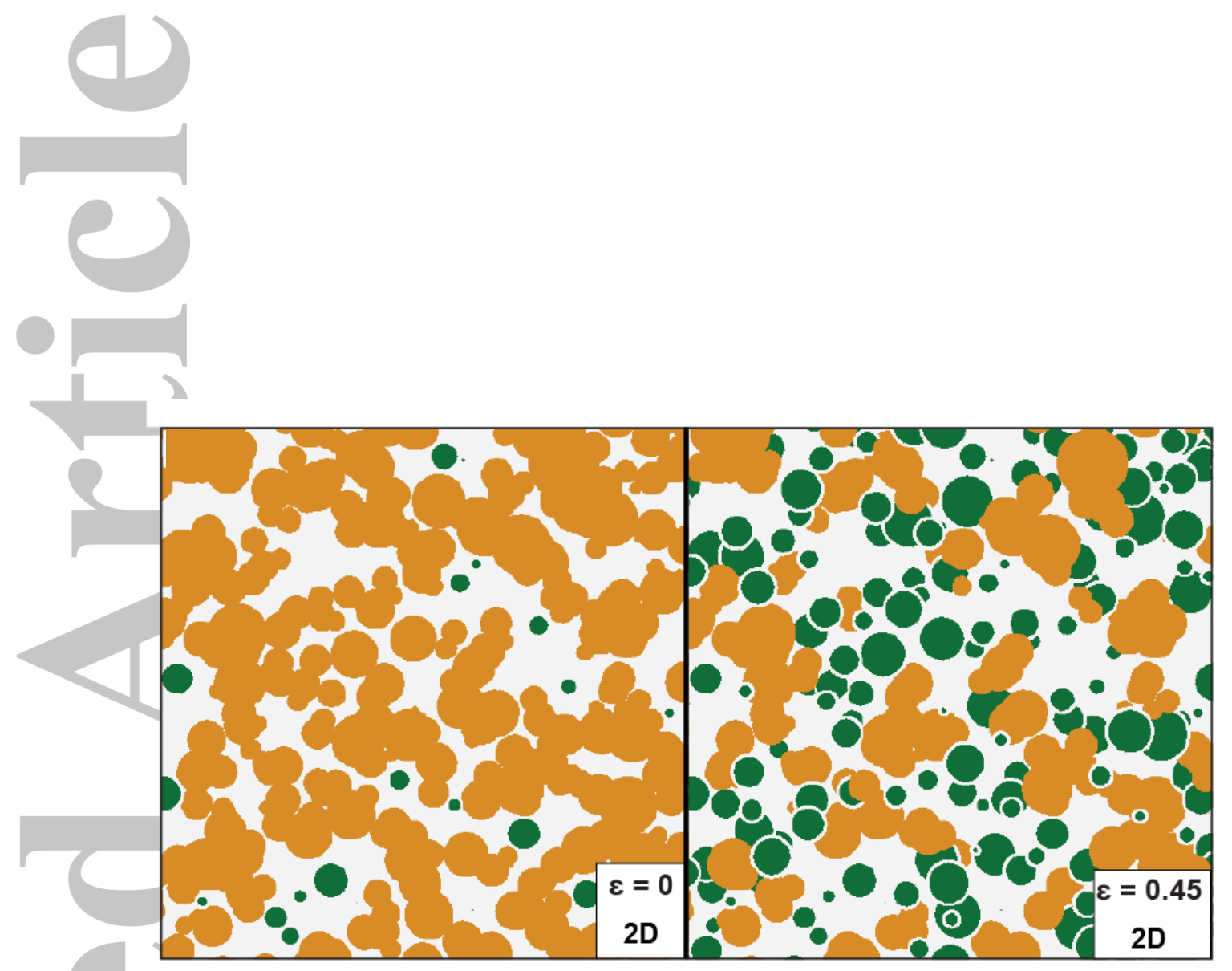

Figure C2. Effect of varying $\varepsilon$ in the percolation model. Portion of a single plane randomly taken inside the virtual cubic domain used for the percolation modeling of sample G-1500 with $\varepsilon=0$ (left) and $\varepsilon=0.45$ (right). Coalesced bubbles are shown in orange and isolated ones in green.

(C)2019 American Geophysical Union. All Rights Reserved. 

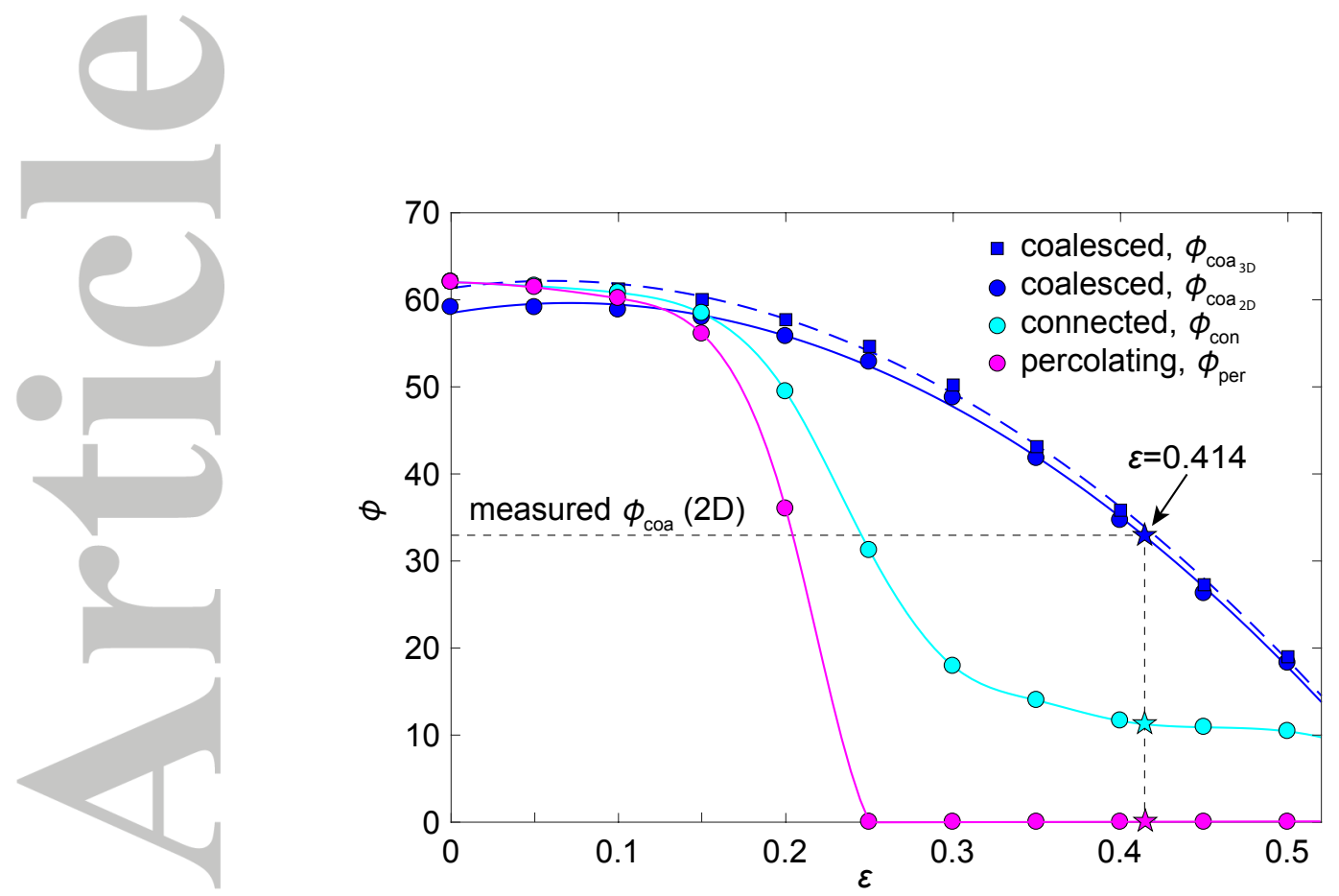

Figure C3. Results of the eleven percolation models run for sample G-1500, which has a measured total and coalesced porosity of $60.5 \%$ and $33.0 \%$, respectively. For $\varepsilon=0$ almost all spheres are coalesced (blue squares), connected to the exterior of the virtual cube (cyan), and percolating (magenta). With increasing $\varepsilon$ the proportion of coalesced, connected, and percolating spheres decreases and the apparent coalesced porosity in 2D (blue circles) better approximates the "true" value in 3D (blue squares). Also shown are interpolations of $\phi_{\text {coa }}, \phi_{\text {con }}$, and $\phi_{\text {per }}$ over $0<\varepsilon<0.5$. At $\varepsilon=0.414$ the modeled coalesced porosity in 2D equals that measured on the SEM images of sample G-1500 (33.0\%). Furthermore, $\phi_{\text {con }}=11.4 \%$ and $\phi_{\text {per }}=0 \%$, that is the sample is impermeable. 